5 Zhaomo Tian ${ }^{1,2} \S$, Tao Wang ${ }^{1 \S}$, Anders Tunlid ${ }^{1} \&$ Per Persson $^{1,2 *}$

$6{ }^{1}$ Department of Biology, Microbial Ecology Group, Lund University, Ecology Building, SE722362 Lund, Sweden

$8{ }^{2}$ Centre for Environmental and Climate Research (CEC), Lund University, Ecology Building, 9 SE-223 62 Lund, Sweden

$11 \S$ These authors contributed equally to this work.

*Corresponding author

14 E-mail: per.persson@biol.lu.se

15 Phone: +46 46-222 1796

Contents (26 pages, 1 table, 21 figures)

S1. Materials and methods

S1.1. Materials

S1.4. Proteolysis of iron oxide-associated BSA in the presence of co-adsorbed phosphate or oxalate

26

$\mathrm{S} 2$. Results and discussion 


\section{S1.1. Materials}

34 Goethite synthesis and characterization. A solution of 2.5 M NaOH was added into a solution 35 of $0.5 \mathrm{M} \mathrm{Fe}\left(\mathrm{NO}_{3}\right)_{3} \cdot 9 \mathrm{H}_{2} \mathrm{O}$ at a rate of $10 \mathrm{ml} \mathrm{min}^{-1}$ until the $\mathrm{pH}$ of the mixture reached 12. 36 During $\mathrm{NaOH}$ addition, the solution was constantly stirred and degassed by $\mathrm{N}_{2}(\mathrm{~g})$ to prevent $37 \mathrm{CO}_{2}$ dissolution and formation of carbonates on the goethite surface. The product was aged at $3860{ }^{\circ} \mathrm{C}$ for one week. The obtained suspension was transferred to a dialysis bag (molecular weight-cutoff: 12000-14000 Da) and dialyzed by replenishing MilliQ water for 2 weeks until the electrical conductivity of the washing water remained constant and below $10 \mu \mathrm{S} \mathrm{m}^{-1}$. The product was transferred to a polyethylene bottle and thoroughly purged with $\mathrm{N}_{2}$ gas to remove carbonate species. The stock suspension was stored at $4{ }^{\circ} \mathrm{C}$. The concentration of the stock was $13.1 \mathrm{~g} \mathrm{l}^{-1}$. The $\mathrm{N}_{2}$ Brunauer- Emmett-Teller (BET) specific surface areas (SSA) was 62 $\mathrm{m}^{2} \mathrm{~g}^{-1}$, which was determined by a Micromeritic Gemini VII 2390a instrument and the BET equation $^{1}$ was applied to calculate SSA.

6-line ferrihydrite synthesis and characterization. 2 liters of Milli-Q in a polyethylene bottle was heated to $75{ }^{\circ} \mathrm{C}$ in the oven. Then $20 \mathrm{~g}$ of $\mathrm{Fe}\left(\mathrm{NO}_{3}\right)_{3} \cdot 9 \mathrm{H}_{2} \mathrm{O}$ was added and dissolved during rapid stirring. This dissolution process lasted for $10-12 \mathrm{~min}$ at $75{ }^{\circ} \mathrm{C}$ and was followed by rapid cooling on ice. The dialysis and storage of the obtained suspension were in accordance with the goethite procedure described above. The SSA of ferrihydrite was estimated to be $300 \mathrm{~m}^{2} \mathrm{~g}^{-1}$ according to the procedure of Krumina et al. ${ }^{2}$ The concentration of the stock was determined to be $1.33 \mathrm{~g} \mathrm{l}^{-1}$. The identity of both ferrihydrite and goethite mineral phases were confirmed by XRD. ${ }^{3}$

\section{S1.2. Batch adsorption experiments}

56 The adsorption of BSA on ferrihydrite and goethite were investigated at $\mathrm{pH} 4.0$ in $0.01 \mathrm{M}$ $\mathrm{NaCl}$ solution. IR spectroscopy indicated that both minerals were stable under these conditions because except for bands assigned to BSA and goethite (ca. 890, 790 and $640 \mathrm{~cm}^{-1}$ ) or ferrihydrite (very broad bands at ca. 690 and $570 \mathrm{~cm}^{-1}$ ) no additional bands appeared during the course of the experiments that could be ascribed to other iron oxide phases, such as akaganeite or lepidocrocite. ${ }^{4}$ Also, the iron oxide-associated BSA seemed to form stable suspensions in the absence of phosphate (Fig. S18). The batch experiments were carried out at 
63 ca. $20{ }^{\circ} \mathrm{C}$ in the dark, and the samples were equilibrated on an end-over-end shaker (PTR-35,

64 Grant Instruments, Cambridge, UK). A BSA stock solution was mixed with ferrihydrite or 65 goethite stock suspensions, giving a final iron oxide concentration of $1 \mathrm{~g} 1^{-1}$. The 66 concentrations of the BSA stock solutions were adjusted to obtain final total BSA 67 concentrations of 200,400,600,800,1000,1250,1500 $\mathrm{mg}^{-1}$ in the presence of ferrihydrite, 68 and 25, 50,100,125,150,200, $250 \mathrm{mg} \mathrm{l}^{-1}$ in the presence of goethite. All samples were 69 equilibrated for $24 \mathrm{~h}$. In order to separate the iron oxide particles from the solution phase after 70 equilibration, $1 \mathrm{ml}$ of iron oxide-BSA suspension was mixed with $0.2 \mathrm{ml}$ of $5 \mathrm{M} \mathrm{NaCl}$ at $\mathrm{pH}$ 714.0 and centrifuged at 13,793 $\times g$ for $5 \mathrm{~min}$ (Heraeus Biofuge 13 centrifuge, Thermo Fisher 72 Scientific, Waltham, MA). The concentration of BSA in the supernatant was determined from 73 the absorbance at $214 \mathrm{~nm}^{5}$ using a UV/visible spectrophotometer (Pharmacia Biotech, 74 Uppsala, Sweden). BSA standards in the range of $25-2000 \mathrm{mg}^{-1}$ were prepared in Milli-Q 75 and the absorbance at $214 \mathrm{~nm}$ was measured to obtain a standard curve, from which the BSA concentrations of the samples were determined. The amount of adsorbed BSA was calculated as the difference between total added BSA and BSA remaining in the solution after adsorption. BSA solutions in the absence of iron oxides were prepared as well and the negligible change in BSA concentration after $24 \mathrm{~h}$ indicated no biotic degradation. Moreover, we detected no

80 BSA degradation products after equilibrating suspensions containing iron oxide-associated 81 BSA for up to 1 month and subsequently analyzing the solution phases with SEC. Thus, the 82 extent of abiotic BSA degradation catalyzed by goethite ${ }^{6}$ was also indicated to be small during the adsorption process under our experimental conditions.

84 Desorption experiment were performed by dispersing the iron oxide-associated BSA in 0.01 $85 \mathrm{M} \mathrm{NaCl}$ solution at $\mathrm{pH}$ 4.0. After equilibrating for $24 \mathrm{~h}$, the liquid phase was collected following centrifugation and filtration, and analyzed for desorbed BSA as described above.

\section{S1.3. Proteolysis of iron oxide-associated BSA.}

Preparation of iron oxide-BSA associations. Iron oxide-associated BSA used in the proteolysis experiments was prepared by adsorbing BSA to either goethite or ferrihydrite surfaces. The adsorption experiment was conducted at $\mathrm{pH} 4.0$ under sterile conditions. The $\mathrm{pH}$ of all solutions and suspensions was adjusted to 4.0 prior to sterilization and mixing. All solutions and the ferrihydrite suspension were filter-sterilized using $0.22 \mu \mathrm{m}$ 94 polyethersulphone (PES) filters (Millipore Inc., Bedford, MA). The goethite suspension was 95 sterilized by autoclaving. The adsorption experiment was performed in a laminar flow cabinet by mixing BSA stock solutions, iron oxide suspensions, $\mathrm{NaCl}$ stock solutions and Milli-Q 
$97(18 \mathrm{M} \Omega \cdot \mathrm{cm})$ at $20{ }^{\circ} \mathrm{C}$, resulting in final concentrations of $1 \mathrm{~g}^{-1}$ of goethite, $0.5 \mathrm{~g}^{-1}$ of 98 ferrihydrite, and $0.01 \mathrm{M} \mathrm{NaCl}$. Two BSA concentrations on each iron oxide were studied, 50 99 and $100 \mathrm{mg} \mathrm{l}^{-1}$ on goethite and 100 and $200 \mathrm{mg}^{-1}$ BSA on ferrihydrite. These concentrations 100 correspond to BSA surface coverage of $0.7 \mathrm{mg} \mathrm{m}^{-2}$ and $1.4 \mathrm{mg} \mathrm{m}^{-2}$ on both iron oxides. The 101 samples were equilibrated for $24 \mathrm{~h}$ at room temperature in the dark on an end-over-end shaker 102 (Grant Instruments). After equilibration, an aliquot of the suspensions containing iron oxideassociated BSA was centrifuged to separate the aqueous phase and iron oxide particles. The aqueous phase was analyzed for remaining BSA but in all cases the aqueous BSA was below the detection limit of SEC as described in the main text. The iron oxides were re-dispersed in $1 \mathrm{ml} 0.01 \mathrm{M} \mathrm{NaCl}$ at $\mathrm{pH} 4.0$ to monitor BSA desorption. These desorption experiments were also performed for $24 \mathrm{~h}$ at room temperature in the dark on an end-over-end shaker (Grant Instruments). After removal of the iron oxides by centrifugation, the filtered supernatants were analyzed for desorbed BSA using both UV/visible spectrophotometry (Pharmacia Biotech) and SEC. We did not detect BSA desorption under any experimental condition.

111 Proteolysis of BSA in solution. One $\mathrm{ml}$ of BSA solution at concentrations of 10, 20, 50 or 100 $112 \mathrm{mg} \mathrm{l}^{-1}$ was reacted with $5 \mathrm{mg} \mathrm{l}^{-1}$ enzyme at $\mathrm{pH} 4.0$ for $3 \mathrm{~h}$ during continuous shaking. The reaction was terminated by increasing the $\mathrm{pH}$ to 7.5 via addition of $0.11 \mathrm{ml}$ phosphate buffer $114\left(0.5 \mathrm{M} \mathrm{Na}_{2} \mathrm{HPO}_{4}\right.$ and $1.5 \mathrm{M} \mathrm{NaCl}$ at $\mathrm{pH}$ 7.5). The samples were subsequently filtered through 115 a $0.2 \mu \mathrm{m} \mathrm{RC}$ filter for SEC analysis. We prepared control samples at $\mathrm{t}=0$ by adding BSA and 116 enzyme sequentially into the phosphate buffer.

117 Hydrolysis of BSA by the iron oxides. Hydrolysis of BSA at $1.4 \mathrm{mg} \mathrm{BSA} \mathrm{m}^{-2}$ and $\mathrm{pH} 4.0$ in $1180.01 \mathrm{M} \mathrm{NaCl}$ was investigated by analyzing the phosphate-desorbed fractions of the iron 119 oxide-associated BSA using SEC as a function of the time. At day 18 and 45 after preparation, one $\mathrm{ml}$ the suspension containing iron oxide-associated BSA was mixed with $0.11 \mathrm{ml}$ of the 121 phosphate buffer $\left(0.5 \mathrm{M} \mathrm{Na}_{2} \mathrm{HPO}_{4}\right.$ and $1.5 \mathrm{M} \mathrm{NaCl}$ at $\left.\mathrm{pH} 7.5\right)$ and shaken for $30 \mathrm{~min}$. The 122 solution phase was separated from the iron oxide particles by centrifugation, filtered and 123 subsequently analyzed using SEC. The SEC chromatograms collected at different time points 124 were compared after area-normalization as described in the main text under the subheading of 125 "size-exclusion chromatography (SEC)".

126 Autoproteolysis of the protease in solution. Protease solutions at a range of concentrations (5, 12710,20 , and $40 \mathrm{mg}^{-1}$ ) were incubated at $\mathrm{pH} 4.0$ for $0,3 \mathrm{~h}$ and $24 \mathrm{~h}$ with occasional vortexing 128 at room temperature. After the incubation, the solutions were mixed with the phosphate buffer $129\left(0.5 \mathrm{M} \mathrm{Na}_{2} \mathrm{HPO}_{4}\right.$ and $1.5 \mathrm{M} \mathrm{NaCl}$ at $\left.\mathrm{pH} 7.5\right)$ and filtered for SEC analysis. 
Hydrolysis of the protease by the iron oxides. The hydrolysis of the protease in the presence

131 of iron oxides was investigated by adding aliquots of the enzyme stock solution into $0.5 \mathrm{~g}^{-1}$ of ferrihydrite or $1 \mathrm{~g} \mathrm{l}^{-1}$ of goethite suspensions to reach final enzyme concentrations of 20 133 and $40 \mathrm{mg} \mathrm{l}^{-1}$ for ferrihydrite or 10 and $20 \mathrm{mg} \mathrm{l}^{-1}$ for goethite. After $3 \mathrm{~h}$ and $24 \mathrm{~h}, 0.11 \mathrm{ml}$ 134 phosphate buffer was added to the suspensions in order to desorb the iron oxide-associated 135 protease and hydrolysis products. The supernatants were subsequently analyzed by means of 136 SEC.

137 Competitive adsorption between BSA and the protease. To investigate the competitive effect 138 of the protease on adsorbed BSA, we deactivated the protease by adding an aspartic protease 139 inhibitor, pepstatin A, in the proteolytic reaction suspension. The protease concentration was $14020 \mathrm{mg}^{-1}$ for goethite and $40 \mathrm{mg} \mathrm{l}^{-1}$ for ferrihydrite. The desorbed BSA concentration was 141 determined in the liquid phase of the suspension after $3 \mathrm{~h}$ and $24 \mathrm{~h}$ using a reversed-phase 142 HPLC, which is capable of efficiently separating BSA and the protease.

\section{S1.4. Proteolysis of iron oxide-associated BSA in the presence of co-adsorbed phosphate} 145 or oxalate.

146 Proteolysis of iron oxide-associated BSA in the presence of co-adsorbed phosphate or oxalate.

147 To investigate the effects of co-adsorbed phosphate or oxalate on the proteolysis of iron oxide-associated BSA, phosphate or oxalate was co-adsorbed with the iron oxide-associated BSA prior to the addition of the enzyme. Four total concentrations of phosphate or oxalate $(0$,

$1501,2,5 \mu \mathrm{mol} \mathrm{m}{ }^{-2}$ ) were investigated. An aliquot of the stock solution of phosphate $(15 \mathrm{mM}$ $\left.151 \mathrm{NaH}_{2} \mathrm{PO}_{4}\right)$ or oxalate $\left(15 \mathrm{mM} \mathrm{Na}_{2} \mathrm{C}_{2} \mathrm{O}_{4}\right)$ was mixed with $1 \mathrm{ml}$ iron oxide-BSA suspension 152 (prepared as aforementioned) at $\mathrm{pH} 4.0$ during continuous shaking for $1.5 \mathrm{~h}$. The iron oxide 153 particles and the solution were separated by centrifugation, and the supernatant was analyzed

154 for desorbed BSA using SEC. Under no experimental conditions did we observe desorption of 155 BSA either by phosphate or oxalate. The adsorbed phosphate or oxalate ions were determined 156 as described below.

157 The iron oxide particles were washed once with water ( $\mathrm{pH} 4.0$ ) to remove non-adsorbed 158 phosphate or oxalate before being re-dispersed into $1 \mathrm{ml}$ water at $\mathrm{pH} 4.0$. To this new 159 suspension, containing either iron oxide-associated BSA with co-adsorbed phosphate or 160 oxalate, we added an aliquot of the protease stock solution to achieve a final enzyme 
161 concentration of $10 \mathrm{mg} \mathrm{l}^{-1}$. Other reaction conditions and analytical procedures were the same as those for the proteolysis experiments as described in the main text.

Proteolysis of BSA in solution in the presence of phosphate or oxalate. The effects of phosphate or oxalate on the proteolysis of aqueous BSA at $\mathrm{pH} 4.0$ were also examined for comparison. These experiments included the additions of comparable amounts of phosphate or oxalate as added in the preceding experiment into a $100 \mathrm{mg}^{-1}$ BSA solution. After the addition of the protease to a final concentration of $10 \mathrm{mg}^{-1}$, the solution was continuously mixed for $3 \mathrm{~h}$. The reaction was terminated by adding $0.11 \mathrm{ml}$ phosphate buffer $(0.5 \mathrm{M}$ $\mathrm{Na}_{2} \mathrm{HPO}_{4}$ and $1.5 \mathrm{M} \mathrm{NaCl}$ at $\mathrm{pH} 7.5$ ), and the hydrolysis products of BSA were analyzed by SEC after filtering through a $0.2 \mu \mathrm{m}$ RC filter.

Determination of the adsorbed phosphate. The concentration of adsorbed phosphate was determined as the difference between the total concentration added and the concentration

173 remaining in solution after adsorption. Phosphate concentration was measured according to 174 the molybdenum blue method. ${ }^{7}$ Samples before adsorption were prepared by adding the 175 corresponding aliquot of phosphate stock solution in $1 \mathrm{ml}$ water at $\mathrm{pH} 4.0$ in the absence of 176 the iron oxide-BSA suspensions. Suspensions after adsorption were centrifuged and the supernatants were filtered through $0.22 \mu \mathrm{m}$ sterile PES filters for the further analysis. All samples before and after adsorption were treated with a reagent consisting of $0.02 \mathrm{M}$ ammonium molybdate, $15 \%$ concentrated $\mathrm{H}_{2} \mathrm{SO}_{4}, 0.31 \mathrm{M}$ L-ascorbic acid and $2.1 \mathrm{mM}$ potassium antimonyl tartrate trihydrate mixed in a 2:5:2:1 volume ratio. $0.1 \mathrm{ml}$ reagent was

181 mixed with $1 \mathrm{ml}$ sample and incubated for $30 \mathrm{~min}$. The absorbance at $885 \mathrm{~nm}$ was recorded 182 on an UV/visible spectrophotometer (Pharmacia Biotech), and the phosphate concentration 183 was obtained from a standard curve made from a series of $\mathrm{NaH}_{2} \mathrm{PO}_{4}$ standard solutions.

184 Determination of the adsorbed oxalate. The concentration of adsorbed oxalate was determined as the difference between the total concentration added and the concentration remaining in solution after adsorption. Oxalate concentration was determined from the UV 187 absorbance at $214 \mathrm{~nm}^{8}$ Oxalate standards in the range of $0-100 \mathrm{mg} \mathrm{l}^{-1}$ were prepared in water 188 at $\mathrm{pH} 4.0$ and the absorbance at $214 \mathrm{~nm}$ was measured to obtain a standard curve, from which 189 the oxalate concentration in the samples were determined. Samples before adsorption were 190 prepared by adding the corresponding aliquot of oxalate stock solution in $1 \mathrm{ml}$ water at $\mathrm{pH} 4.0$ 191 in the absence of the iron oxide-BSA suspensions. Suspensions after adsorption were centrifuged and the subsequent $0.9 \mathrm{ml}$ of supernatants were mixed with $0.1 \mathrm{ml}$ phosphate buffer $\left(0.5 \mathrm{M} \mathrm{Na}_{2} \mathrm{HPO}_{4}\right.$ and $1.5 \mathrm{M} \mathrm{NaCl}$ at $\mathrm{pH} \mathrm{7.5)}$ and centrifuged again. This second 
centrifugation was aimed to remove the iron oxides nanoparticles remaining in the

195 supernatants by precipitating them with phosphate. Still, after filtration through a $0.22 \mu \mathrm{m}$ sterile PES filter the supernatants contained some iron oxides nanoparticles, which unavoidably contributed to the absorbance at $214 \mathrm{~nm}$ and thus interfered with the oxalate results. Such interference was especially significant at oxalate concentrations above $1 \mu \mathrm{mol} \mathrm{m}$ 2 and was larger for ferrihydrite than goethite.

\section{S1.5. Analytical techniques.}

202 Size-exclusion chromatography (SEC). SEC was used to monitor concentration changes of 203 BSA and its degradation products in solution. The SEC measurements were performed on a 204 HPLC system (Ultimate 3000; Thermo Scientific, Waltham, MA) equipped with a Superdex 20575 column (GE Healthcare Life Sciences, Little Chalfont, UK). Data were recorded at $214 \mathrm{~nm}$ using a diode array detector (Ultimate 3000). A phosphate buffer (0.05 M phosphate in 0.15 $\mathrm{M} \mathrm{NaCl}$ at $\mathrm{pH} 8.5$ ) was used as the mobile phase and the flow rate was $100 \mu \mathrm{min}^{-1}$. The column was calibrated using a low-molecular-weight gel filtration calibration kit (GE Healthcare, Chicago, IL). The molecular size standards included: Conalbumin (75 kDa),

210 Ovalbumin (43 kDa), Carbonic Anhydrase (29 kDa), Ribonuclease A (13.7 kDa), and 211 Aprotinin $(6.5 \mathrm{kDa})$. In order to compare results between samples the obtained 212 chromatograms of the phosphate-desorbed fractions were normalized according to the areas 213 between the retention times 8-18 $\min$ (in the presence of oxalate the range 8-16 min was used), 214 which encompassed peaks of intact BSA and most of its degradation products.

215 Reversed-phase HPLC (RP-HPLC). A reversed-phase column (Kinetex C18, $150 \times 4.6 \mathrm{~mm}$, $2162.6 \mu \mathrm{m}$. Phenomenex, Torrance, CA) was used to separate BSA from the protease. The 217 injection volume was $125 \mu$. The binary gradient (A: $0.1 \%$ TFA in water and B: $0.1 \%$ TFA in acetonitrile) was held at $35 \% \mathrm{~B}$ for $5 \mathrm{~min}$, then increased from $35 \%$ to $65 \% \mathrm{~B}$ in $7 \mathrm{~min}$ and maintained at $65 \% \mathrm{~B}$ for $4 \mathrm{~min}$, then decreased from $65 \%$ to $35 \% \mathrm{~B}$ in $2 \mathrm{~min}$, and finally continued at $35 \% \mathrm{~B}$ for $7 \mathrm{~min}$. The flow rate was $0.5 \mathrm{ml} \mathrm{min}^{-1}$. UV absorbance at $220 \mathrm{~nm}$ was collected.

223 Infrared (IR) spectroscopy. The adsorption, desorption, and proteolysis of iron oxide224 associated BSA was studied in-situ by the attenuated total reflectance (ATR) technique. The 225 experimental setup consisted of an FTIR spectrometer (VERTEX 80v; Bruker, Ettlingen, 
226 Germany) and a single-reflection $45^{\circ}$ ATR accessory (FastIR, Harrick Scientific, NY). The 227 ATR crystal ( $\mathrm{ZnSe}$ ) formed the bottom of a home-built titration vessel and the vessel was 228 attached to the ATR accessory, which was mounted in the sample compartment. The interior 229 of the spectrometer, including the sample compartment, was evacuated to ca. $140 \mathrm{~Pa}$ in order 230 to minimize the spectral contributions from $\mathrm{H}_{2} \mathrm{O}(\mathrm{g})$ and $\mathrm{CO}_{2}(\mathrm{~g})$; note that the sample in the 231 titration vessel was not subjected to low pressures. A film of goethite on the ATR crystal was 232 prepared by drop-casting $0.7 \mathrm{ml}$ of $2 \mathrm{~g} \mathrm{l}^{-1}$ on the ZnSe crystal, and the film was subsequently 233 dried in a desiccator for approximately $72 \mathrm{~h}$. Once assembled in the spectrometer, $5 \mathrm{ml}$ 234 background solution of $0.01 \mathrm{M} \mathrm{NaCl}$ (pre-adjusted to $\mathrm{pH} 4.0$ ) was pipetted into the titration 235 vessel and equilibrated with the goethite film for ca. $40 \mathrm{~h}$. A propeller stirrer gently stirred the 236 solution phase and the headspace of the vessel was purged with $\mathrm{N}_{2}$ during all experiments. 237 The experiments were conducted at room temperature $\left(\sim 20^{\circ} \mathrm{C}\right)$. The stability of the film was 238 monitored via the strong IR bands of goethite at 795 and $895 \mathrm{~cm}^{-1}$. After equilibrium was 239 reached between the goethite film and the $\mathrm{NaCl}$ solution, a background spectrum was 240 collected (1024 scans/spectrum at a resolution of $\left.4 \mathrm{~cm}^{-1}\right)$.

241 BSA adsorption was initiated by adding an aliquot of BSA stock solution into the vessel 242 during continuous stirring. Two total BSA concentrations ( 0.7 and $1.4 \mathrm{mg} \mathrm{BSA} \mathrm{m}^{-2}$ goethite) 243 were investigated. The experiments were terminated after $24 \mathrm{~h}$. The adsorption solution was 244 removed and the film was cleaned with $15 \mathrm{ml}$ of $\mathrm{NaCl}$ solution (0.01 M, pH 4.0). The 245 desorption experiment was started after addition of $2 \mathrm{ml}$ of $0.01 \mathrm{M} \mathrm{NaCl}$ solution into the 246 vessel. The negligible spectral change observed during the following $24 \mathrm{~h}$ indicated no or 247 very slow desorption. The ferrihydrite experiments were conducted following the same 248 methods as the goethite experiments, but only for the adsorption step due to instabilities of the 249 ferrihydrite films, as observed mainly by an increasing interference from the strong water 250 bending mode at $1630 \mathrm{~cm}^{-1}$ during the comparatively long total experimental times required 251 to monitor desorption and proteolysis $(>130 \mathrm{~h})$.

252 The proteolysis of adsorbed BSA on the goethite film was monitored continuously for $c a$. 20 $253 \mathrm{~h}$ after addition of an aliquot of the protease stock solution. One identical protease 254 concentration was studied for both BSA surface coverages, corresponding to $1 / 10$ and $1 / 20$ $255(\mathrm{w} / \mathrm{w})$ of the amount of adsorbed BSA. Each spectrum was an average spectrum of 512 scans 256 (ca. $7 \mathrm{~min} /$ spectrum).

257 The effect of co-adsorbed phosphate on the proteolysis of goethite-associated BSA was also 258 investigated using the in-situ IR technique. The experimental procedures were the same as 
259 described above except that $1 \mu \mathrm{mol} \mathrm{m}{ }^{-2}$ of phosphate was added and adsorbed on the goethite 260 for ca. $20 \mathrm{~h}$ prior to the addition of the protease.

261 The spectral data sets were cut between $920-1850 \mathrm{~cm}^{-1}$ and offset-normalized using the range 262 1850-1800 $\mathrm{cm}^{-1}$ in OPUS software (v 7.2, Bruker, Billerica, MA). These pre-processed 263 spectral sets were analyzed by a multivariate curve resolution alternating least squares (MCR264 ALS) formalism as implemented in the Matlab program PLS Toolbox v. 8.6 (Eigenvector 265 Research, Inc). MCR-ALS resolved the data sets into component spectra contributing to the 266 spectral variation and their corresponding contribution profiles. Non-negative constraints 267 were applied for both the contributions and the spectra, and the modeling was performed with 268 the constraint to obtain maximum contrast in the spectral dimension. Duplicate experiments 269 were performed. Due to the variation in the thickness of goethite films, the overall IR 270 intensity of the duplicates varied. Therefore, we analyzed the spectra of each data set 271 separately. The resolved MCR component spectra and their corresponding contribution 272 profiles showed similar patterns between replicates (see Fig. S13), but for the sake of clarity 273 we present results from only one data set in the main text. 


\section{S2. Results and discussion}

\section{Supporting table}

282 Table S1. Enzyme concentrations remaining in solution of suspensions containing ferrihydriteassociated or goethite-associated BSA, in absence and presence of pre-adsorbed phosphate or oxalate, after $3 \mathrm{~h}$ proteolysis reaction at increasing concentrations of protease. The enzyme concentrations were determined from the intensities of the peak corresponding to ca. $70 \mathrm{kDa}$ in the SEC chromatograms as specified in Column 1.

\begin{tabular}{|l|l|l|l|l|}
\hline \multirow{2}{*}{$\begin{array}{l}\text { Corresponding } \\
\text { figure }\end{array}$} & \multirow{2}{*}{$\begin{array}{l}\text { Added enzyme } \\
\text { conc. }\left(\mathrm{mg} \mathrm{l}^{-1}\right)\end{array}$} & $\begin{array}{l}\text { Added phosphate or } \\
\text { oxalate }\left(\mu \mathrm{mol} \mathrm{m} \mathrm{m}^{-2}\right)\end{array}$ & \multicolumn{2}{|l|}{ Remaining enzyme conc. $\left(\mathrm{mg}^{-1}\right)$} \\
\cline { 4 - 6 } & & NA & Ferrihydrite & Goethite \\
\hline Fig. S10 & 10 & NA & BD & BD \\
\hline Fig. S10 & 20 & 1 (phosphate) & $5.1(1.1)$ & $6.4(1.4)$ \\
\hline Fig. S16 & 10 & 1 (oxalate) & $2.1(0.4)$ & $3.7(1.0)$ \\
\hline Fig. S20 & 10 & & $2.7)$ & $6.8(0.6)$ \\
\hline
\end{tabular}




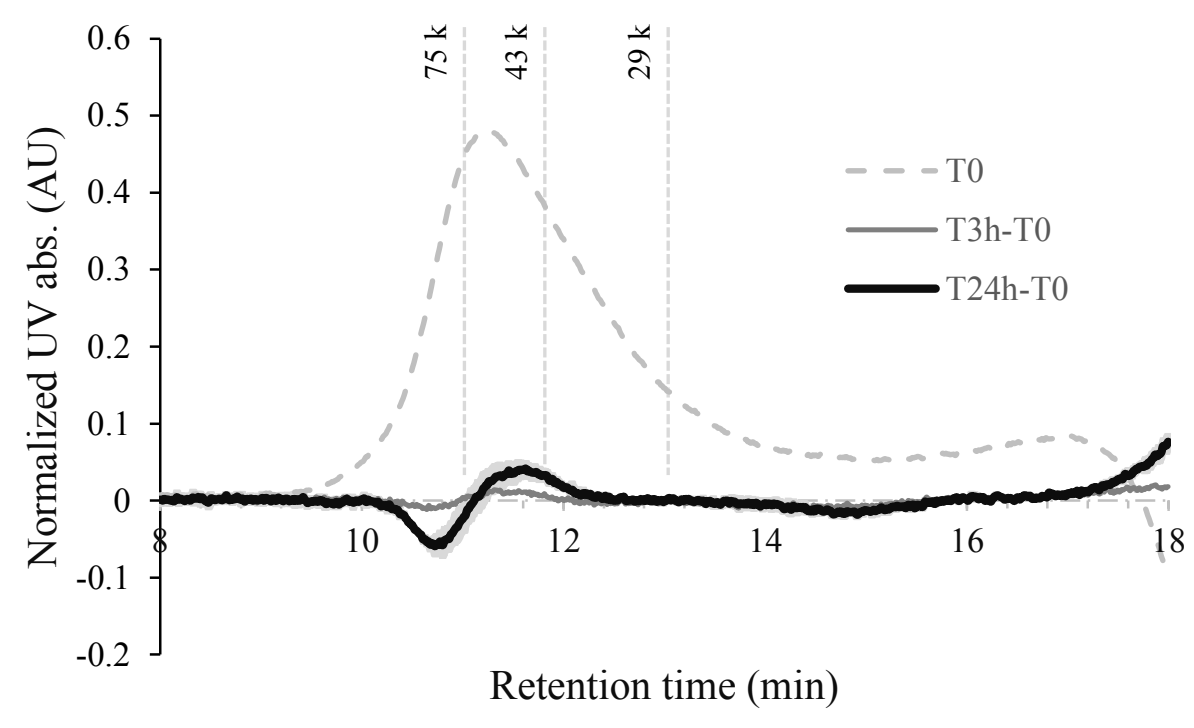

295 Figure S1. SEC chromatograms of a freshly prepared protease solution (T0, dashed line), and 296 after $3 \mathrm{~h}$ and $24 \mathrm{~h}$ at room temperature in the dark. The protease concentration was $40 \mathrm{mg} \mathrm{l}^{-1}$, 297 which was the maximum enzyme concentration used in the study. Data were area-normalized 298 in order to minimize small effects of protease adsorption onto container walls. The difference 299 chromatograms were calculated by subtracting the T0 chromatogram from those obtained 300 after $3 \mathrm{~h}$ (T3) and $24 \mathrm{~h}$ (T24). Shaded bands represent standard deviations (n=2). The 301 molecular masses (in $\mathrm{Da}$ ) of peptide standards are represented by the vertical dotted lines. 


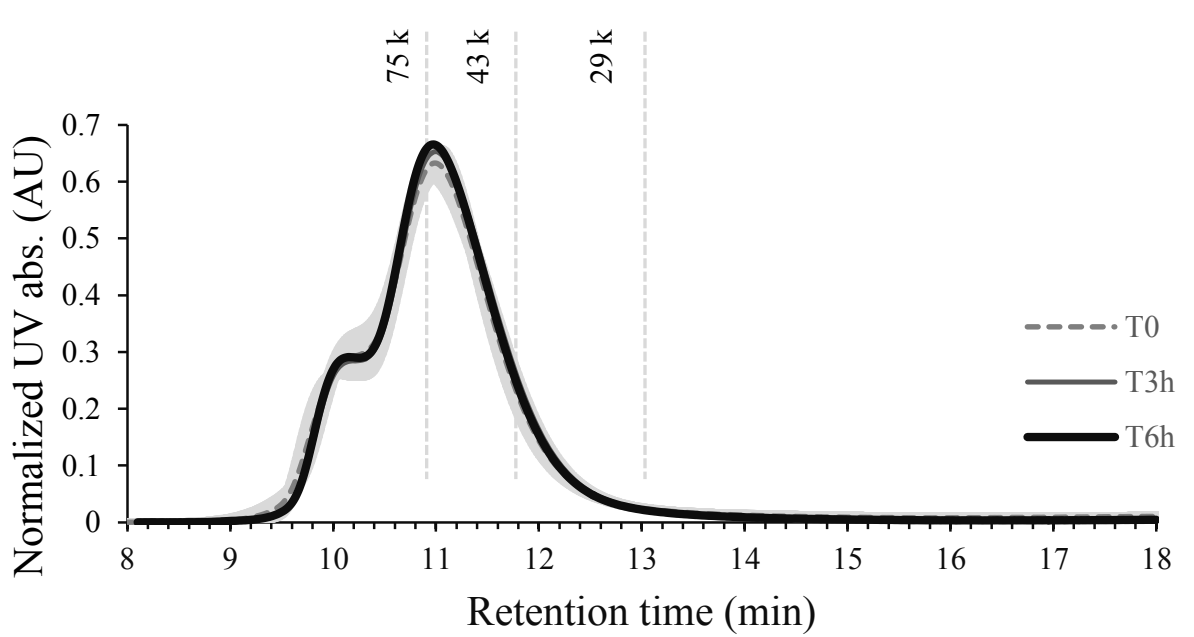

303

304

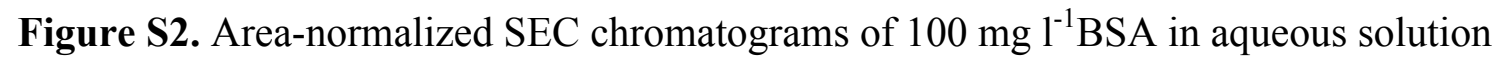
before (T0) and after $3 \mathrm{~h}(\mathrm{~T} 3 \mathrm{~h})$ and $6 \mathrm{~h}(\mathrm{~T} 6 \mathrm{~h})$ proteolysis reaction at $\mathrm{pH} 7.5$ in $0.01 \mathrm{M} \mathrm{NaCl}$ and at a protease concentration of $10 \mathrm{mg} \mathrm{l}^{-1}$. Data indicate that negligible proteolysis occurs at $\mathrm{pH}$ 7.5. Accordingly, we terminate the proteolysis reactions for all experiments throughout the manuscript by the rapid $\mathrm{pH}$ increase to 7.5. The shaded bands represent standard deviations ( $\mathrm{n}=2$ ). The molecular masses (in $\mathrm{Da}$ ) of peptide standards are represented by the vertical dotted lines.

(A)

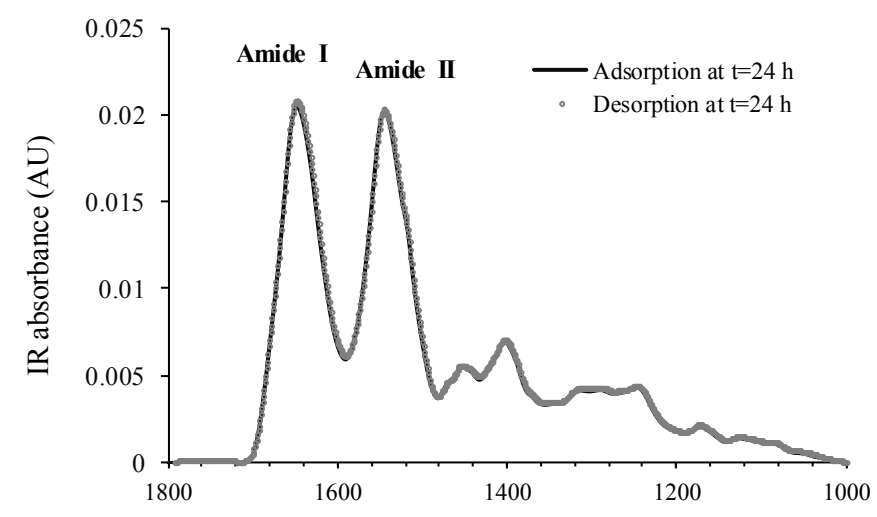

Wavenumber $\left(\mathrm{cm}^{-1}\right)$
(B)

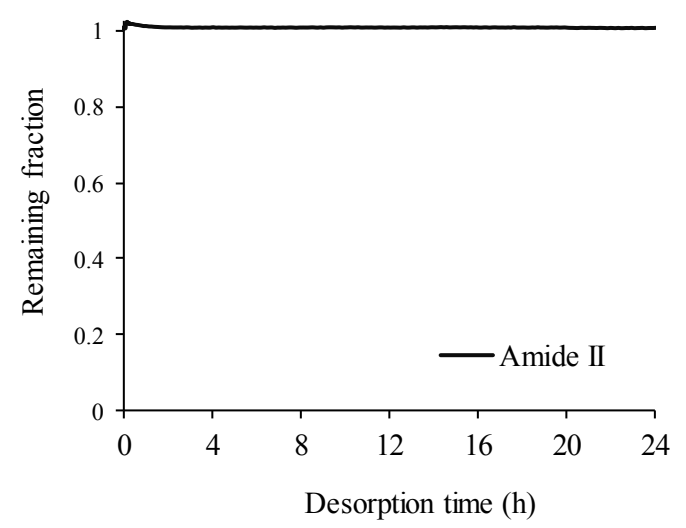

Figure S3. IR spectroscopic results of BSA adsorption and desorption from goethite. The experiments were performed for $24 \mathrm{~h}$ at a BSA surface coverage of $1.4 \mathrm{mg} \mathrm{m}^{-2}$ and $\mathrm{pH} 4.0$ in $0.01 \mathrm{M} \mathrm{NaCl}$. (A) Averages of the last $10 \mathrm{IR}$ spectra collected at the end of the adsorption 316 (solid line) and desorption (dotted line) processes. Shaded bands represent standard deviations $317(\mathrm{n}=10)$. (B) The intensity change of amide II $\left(1545 \mathrm{~cm}^{-1}\right)$ bands during $24 \mathrm{~h}$-desorption as a 318 function of time. All intensities are normalized to the intensity at $t_{\text {desorption }}=0$. 
(A)

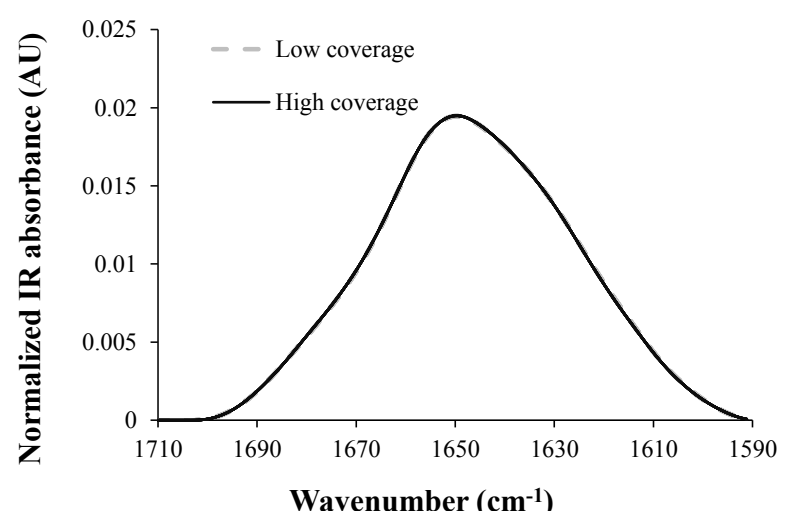

(B)

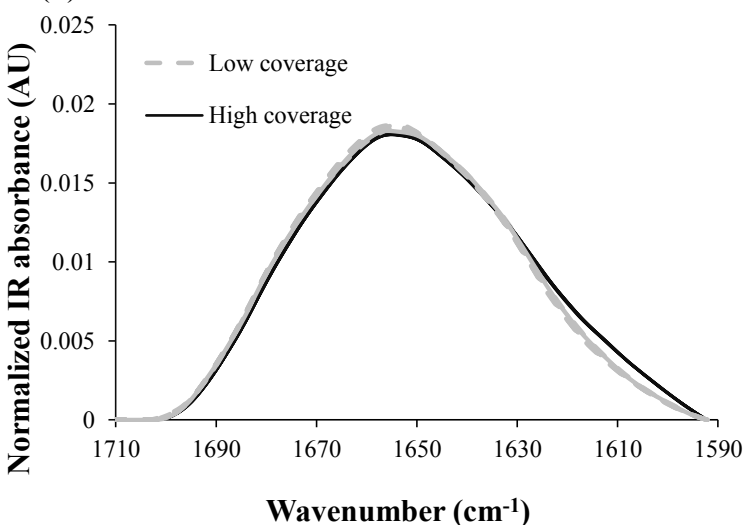

321 Figure S4. Area normalized amide I IR band $\left(1710-1590 \mathrm{~cm}^{-1}\right)$ of goethite-associated BSA 322 (A) and ferrihydrite-associated BSA (B) at 0.7 (low coverage) and $1.4 \mathrm{mg} \mathrm{BSA} \mathrm{m}^{-2}$ (high 323 coverage). For each coverage, the last 10 spectra collected at the end of the adsorption 324 experiments $(\mathrm{t}=24 \mathrm{~h})$ are shown. The experiments were performed at $\mathrm{pH} 4.0$ in $0.01 \mathrm{M} \mathrm{NaCl}$. 

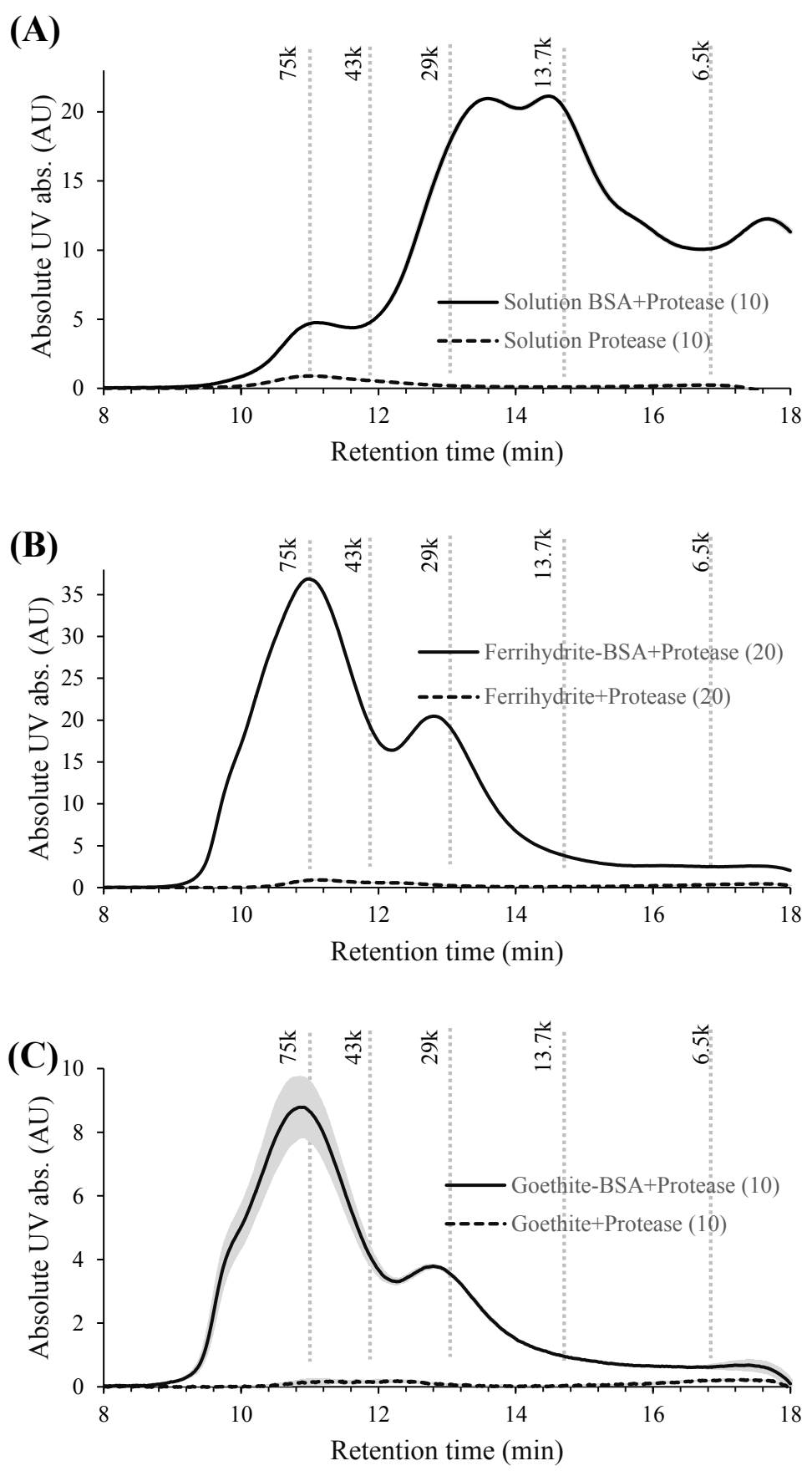

327 Figure S5. SEC chromatograms of BSA in solution (100 $\left.\mathrm{mg}^{-1}\right)$ (A) and the phosphate328 desorbed fraction of ferrihydrite-associated BSA (B) and goethite-associated BSA (C) after 3 $329 \mathrm{~h}$ proteolysis reaction (solid lines). SEC chromatograms of a protease in solution and the 330 phosphate-desorbed fraction of ferrihydrite-associated protease (B) and goethite-associated 331 protease (C) after $24 \mathrm{~h}$ hydrolysis of the protease by the iron oxides (dotted lines) are also 332 shown for comparison. The total protease concentrations are indicated in the figure legends 333 and given in $\mathrm{mg}^{-1}$. Shaded bands represent standard deviations $(\mathrm{n}=2)$. The molecular masses 334 (in Da) of peptide standards are represented by the vertical dotted lines. 
(A)

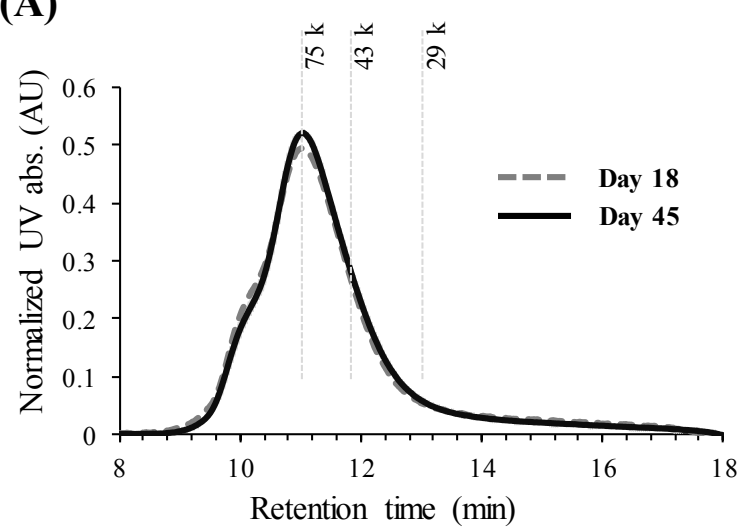

(B)

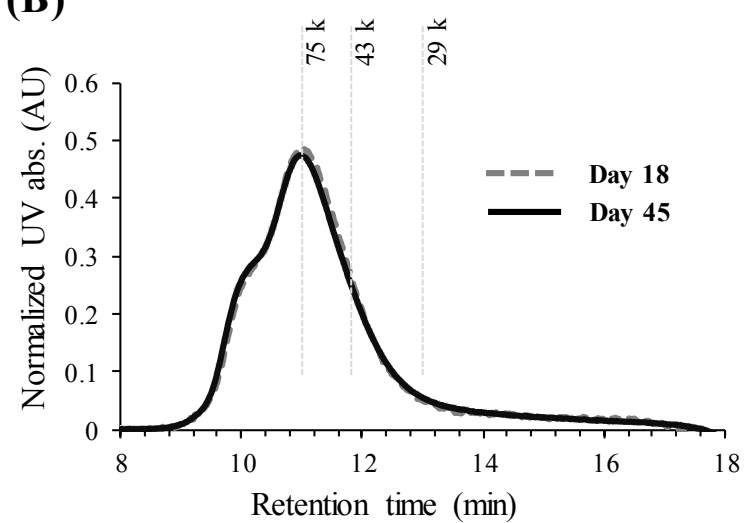

Figure S6. SEC chromatograms of the phosphate-desorbed fraction of ferrihydrite-associated BSA (A) and goethite-associated BSA (B) at a surface coverage of $1.4 \mathrm{mg} \mathrm{BSA} \mathrm{m}{ }^{-2}$ and $\mathrm{pH}$ 4.0 in $0.01 \mathrm{M} \mathrm{NaCl}$ at day 18 and 45 after preparation. Shaded bands represent standard deviations $(n=2)$ and may not be visible due to the small standard deviations. The molecular masses (in Da) of peptide standards are represented by the vertical dotted lines.

(A)

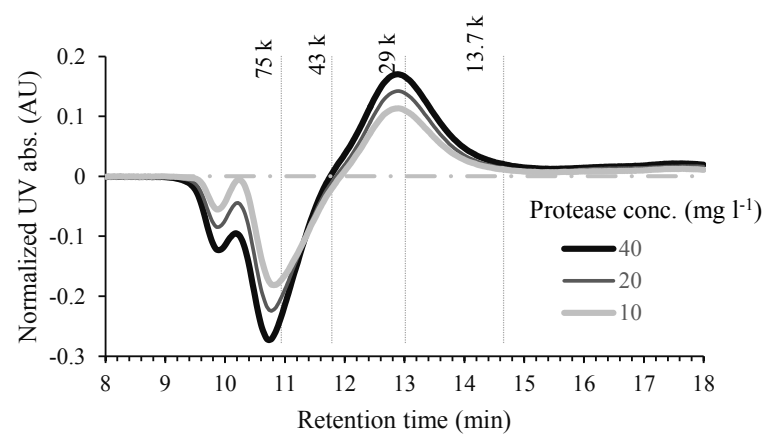

(B)

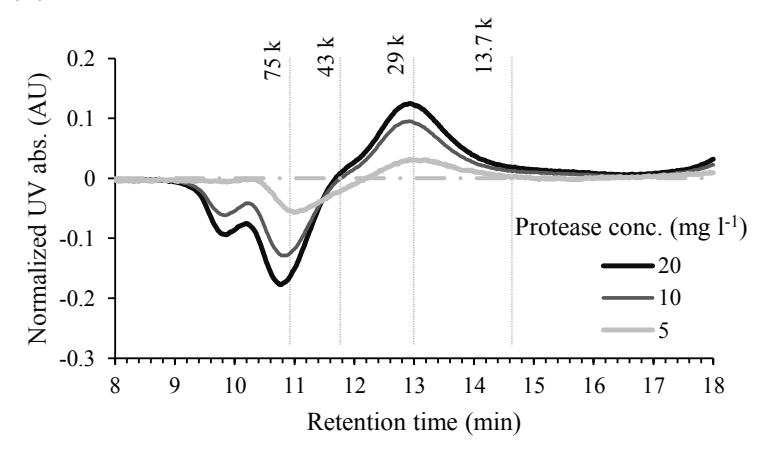

343 Figure S7. Difference SEC chromatograms of the phosphate-desorbed fraction of

344 ferrihydrite-associated BSA (A) and goethite-associated BSA (B) after $3 \mathrm{~h}$ proteolysis 345 reaction with increasing concentrations of protease; the protease concentrations are indicated 346 in the figure legends and given in $\mathrm{mg}^{-1}$. The experiments were performed at a BSA surface 347 coverage of $1.4 \mathrm{mg} \mathrm{m}^{-2}$ at $\mathrm{pH} 4.0$ in $0.01 \mathrm{M} \mathrm{NaCl}$. The difference chromatograms were 348 calculated from normalized data and by subtracting the chromatogram at T0. The horizontal 349 dotted lines indicate the 0 -level. The shaded bands represent standard deviations $(n=2)$. The 350 molecular masses (in Da) of peptide standards are represented by the vertical dotted lines. 
(A)

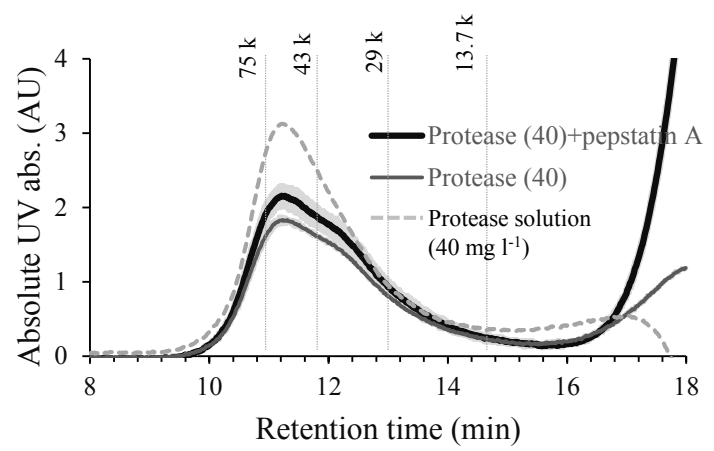

(B)

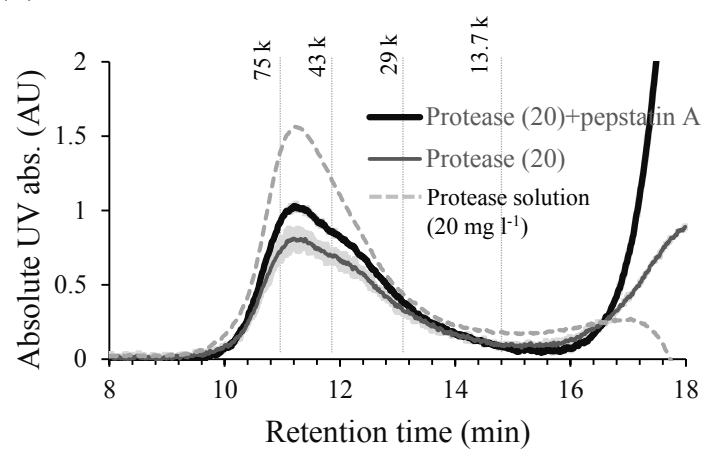

Figure S8. SEC chromatograms of ferrihydrite-associated BSA (A) and goethite-associated $354 \mathrm{BSA}(\mathrm{B})$ at $1.4 \mathrm{mg} \mathrm{BSA} \mathrm{m}^{-2}$ and $\mathrm{pH} 4.0$ in $0.01 \mathrm{M} \mathrm{NaCl}$ after $3 \mathrm{~h}$ proteolysis in the absence 355 (thin grey solid lines) and the presence of the aspartic protease inhibitor, pepstatin A (thick 356 black solid lines). Dotted lines show SEC chromatograms of protease solutions. The total 357 protease concentrations are indicated in the figure legends and are given in $\mathrm{mg}^{-1}$. Shaded 358 bands represent standard deviations $(\mathrm{n}=2)$. The molecular masses (in Da) of peptide standards 359 are represented by the vertical dotted lines. Intensity increases after 16 min originate from 360 pepstatin A or the formation of low-molecular-weight hydrolysis products in the presence and 361 absence of pepstatin A, respectively. The intensity decrease of the reference protease solution 362 at $17 \mathrm{~min}$ and onwards was caused by solvent effects.
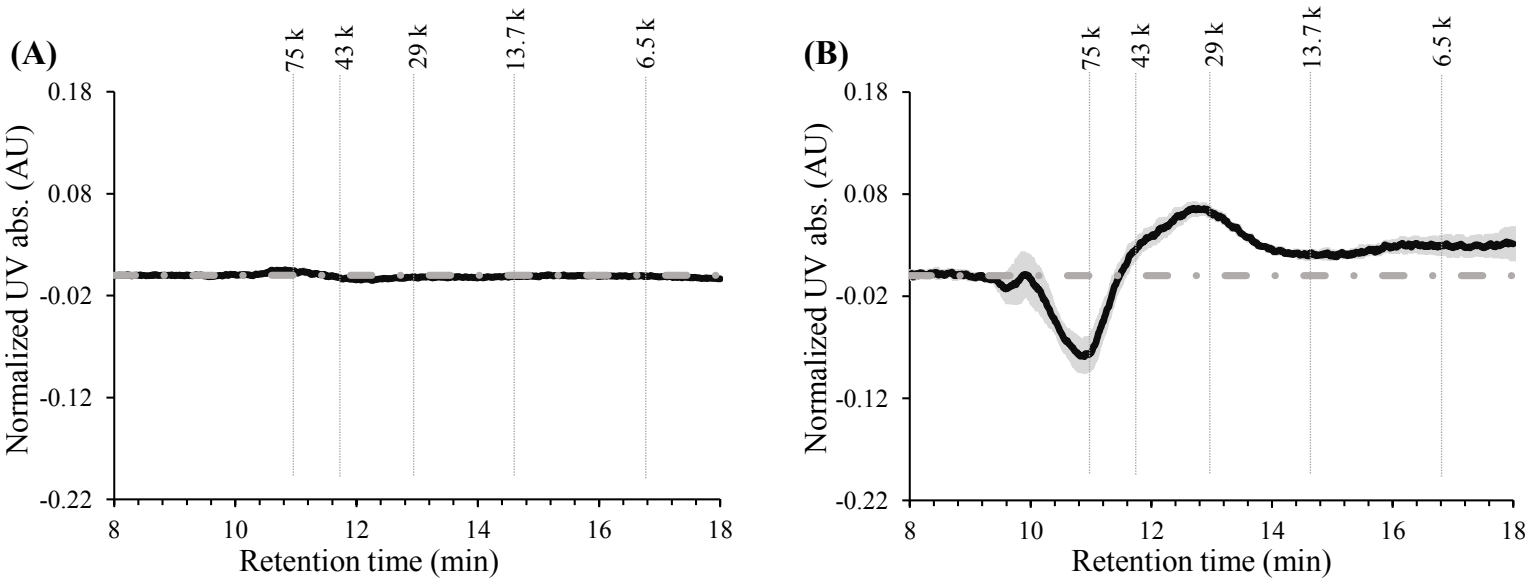

365 Figure S9. Difference SEC chromatograms of the phosphate-desorbed fraction of ferrihydrite-associated BSA (A) and goethite-associated BSA (B) at $0.7 \mathrm{mg} \mathrm{BSA} \mathrm{m}^{-2}$ and $\mathrm{pH}$ 4.0 in $0.01 \mathrm{M} \mathrm{NaCl}$, after $3 \mathrm{~h}$ proteolysis reaction. The protease concentration was $10 \mathrm{mg} \mathrm{l}^{-1}$. 
368 The difference chromatograms were obtained by subtracting the normalized chromatograms 369 at $\mathrm{t}=0 \mathrm{~h}$ from that at $3 \mathrm{~h}$ (cf. Fig. 2). The horizontal dotted lines indicate the 0 -level. Shaded 370 bands represent standard deviations $(n=2)$. The molecular masses (in Da) of peptide standards 371 are represented by the vertical dotted lines.

(A)

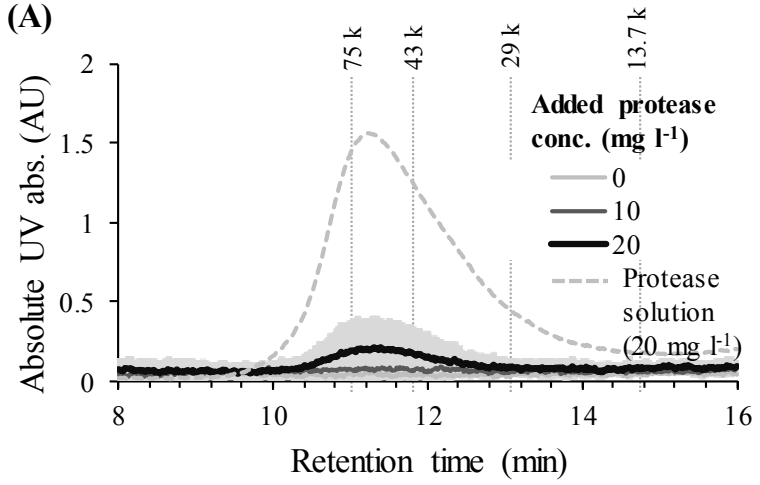

(B)

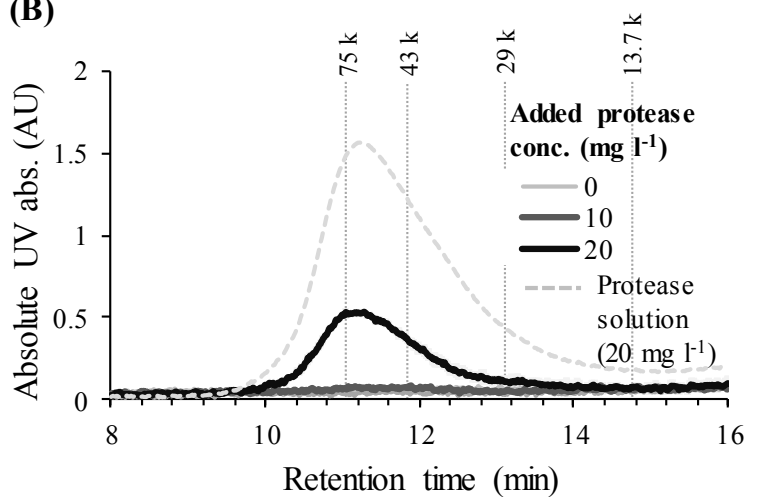

373

374 Figure S10. SEC chromatograms of ferrihydrite-associated BSA (A) and goethite-associated 375 BSA (B) after $3 \mathrm{~h}$ proteolysis reaction at increasing concentrations of protease. The protease 376 concentrations are indicated in the figure legends and given in $\mathrm{mg}^{-1}$. The experiments were 377 performed at a BSA surface coverage of $0.7 \mathrm{mg} \mathrm{m}^{-2}$ and $\mathrm{pH} 4.0$ in $0.01 \mathrm{M} \mathrm{NaCl}$. Dotted lines 378 show SEC chromatograms of a protease solution $\left(20 \mathrm{mg} \mathrm{l}^{-1}\right)$. The shaded bands represent 379 standard deviations $(\mathrm{n}=2)$. The molecular masses (in Da) of peptide standards are represented 380 by the vertical dotted lines. 
(A)

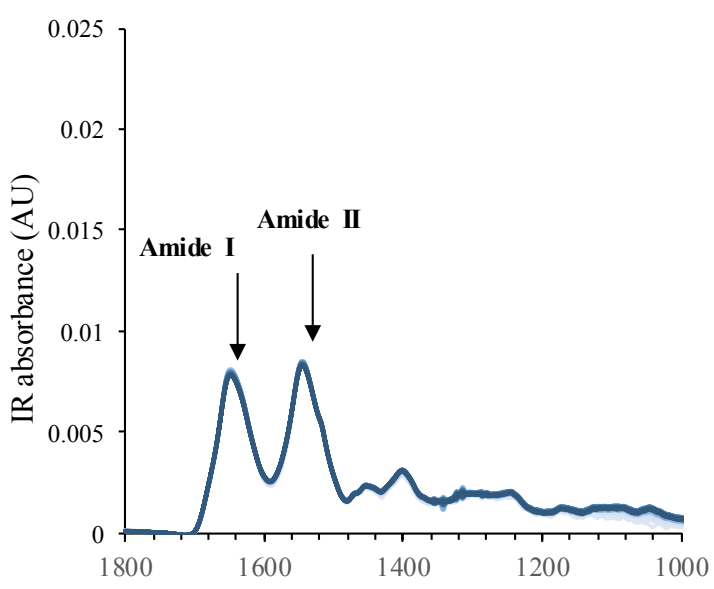

Wavenumber $\left(\mathrm{cm}^{-1}\right)$
(B)

High coverage

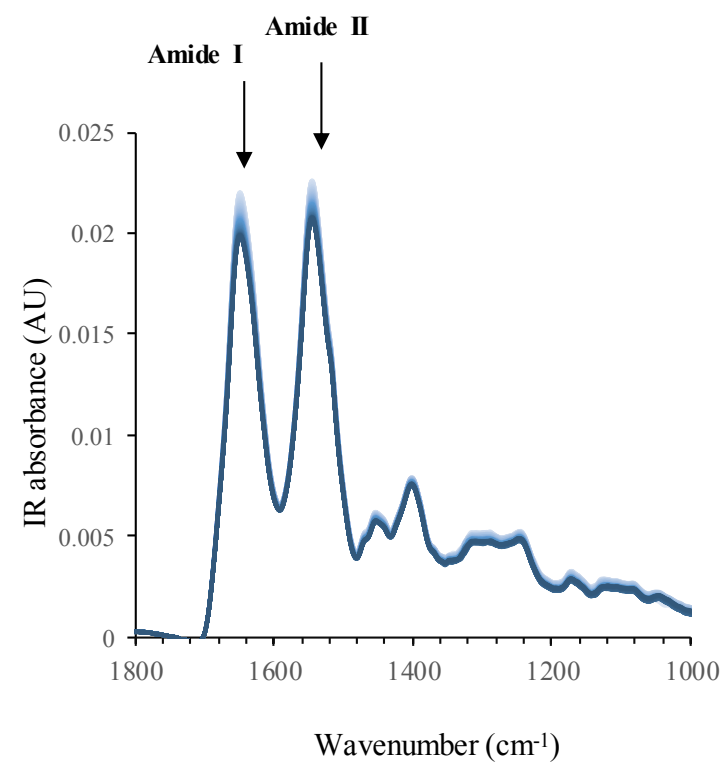

Figure S11. IR spectra of goethite-associated BSA at different time points during $20 \mathrm{~h}$ 384 proteolysis at 0.7 (A, low coverage) and $1.4 \mathrm{mg} \mathrm{BSA} \mathrm{m}^{-2}(\mathrm{~B}$, high coverage) and $\mathrm{pH} 4.0$ in $3850.01 \mathrm{M} \mathrm{NaCl}$. Arrows indicate the direction of change of amide I and amide II as a function of 386 time.

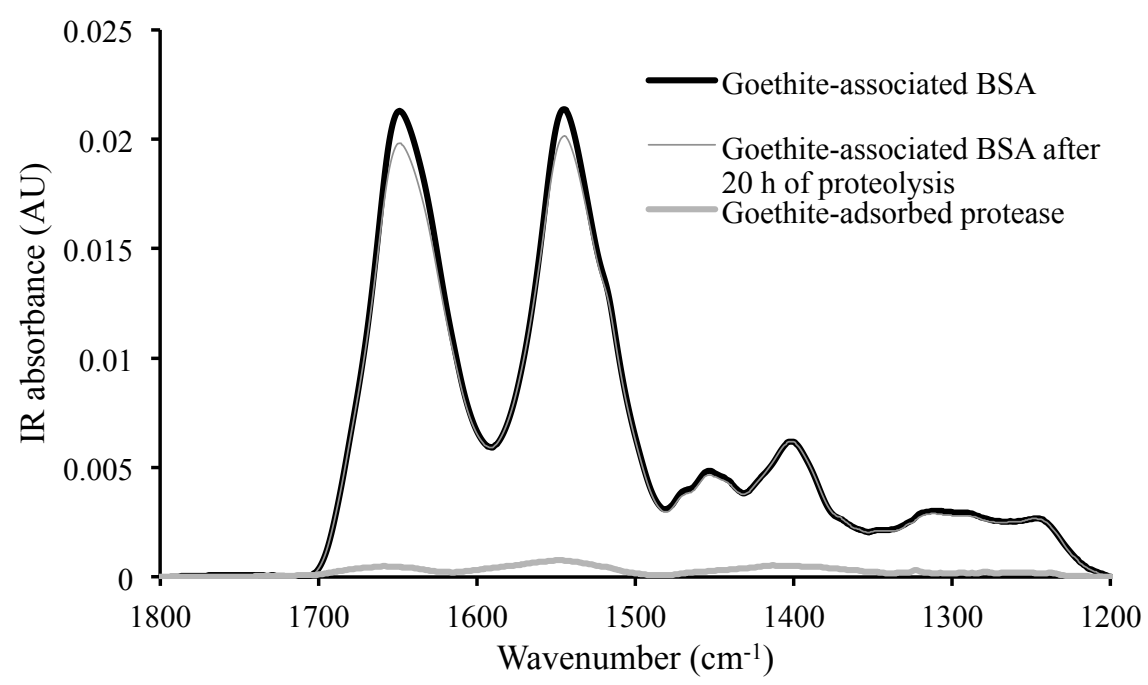

389 Figure S12. IR spectra of goethite-associated BSA at $1.4 \mathrm{mg} \mathrm{m}^{-2}$ before and after $20 \mathrm{~h}$ 390 proteolysis reaction, and of adsorbed protease. The adsorption of protease was conducted 391 using a clean goethite film in absence of BSA. The protease concentrations in both the proteolysis experiment and the adsorption experiment were the same, equal to $5 \%$ of the total 
393 BSA concentration i.e. $0.07 \mathrm{mg} \mathrm{m}^{-2}$ and this represents the highest protease concentration 394 used in any of the IR experiments.

395 
Proteolysis in absence of adsorbed phosphate
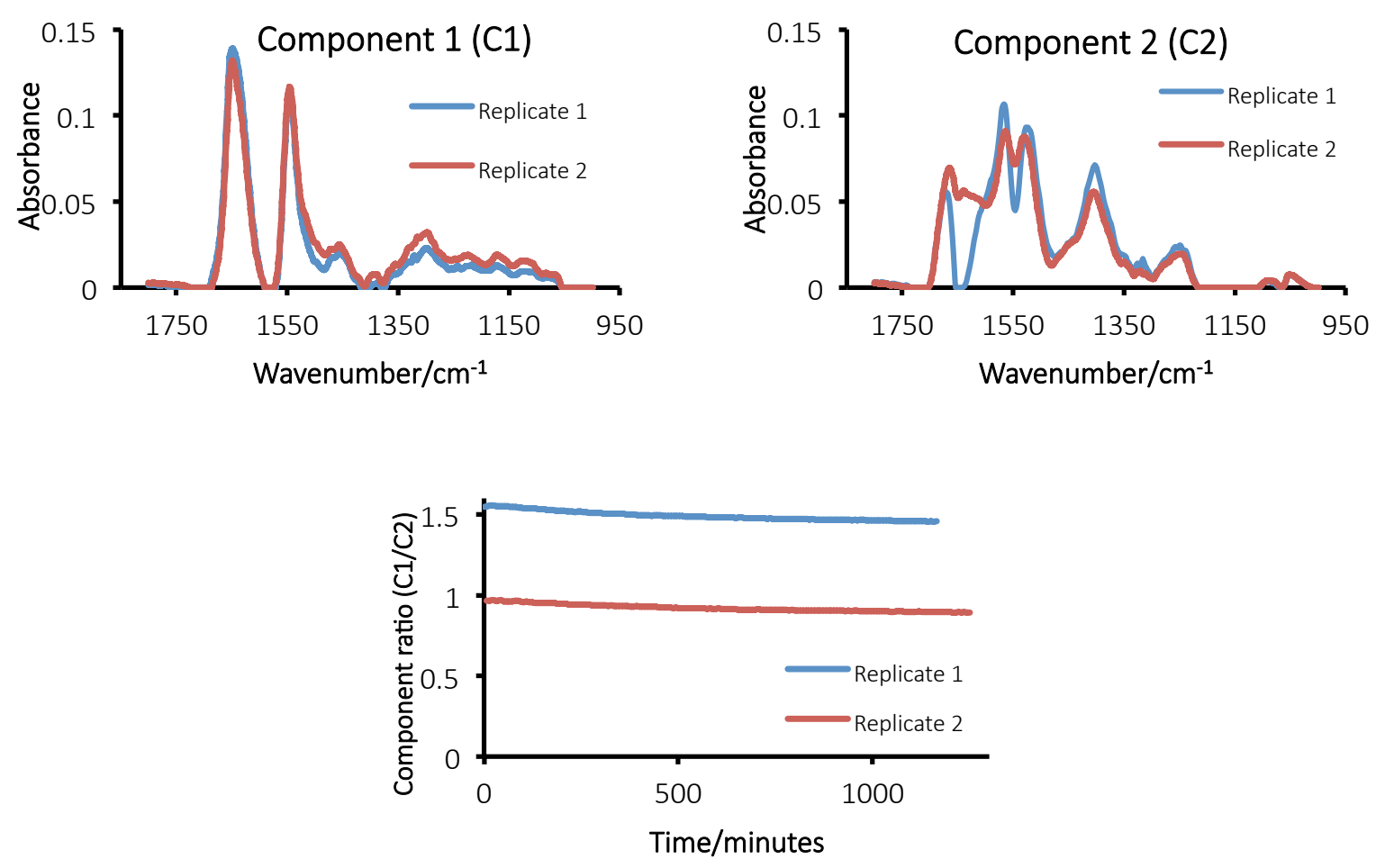

Proteolysis in presence of adsorbed phosphate
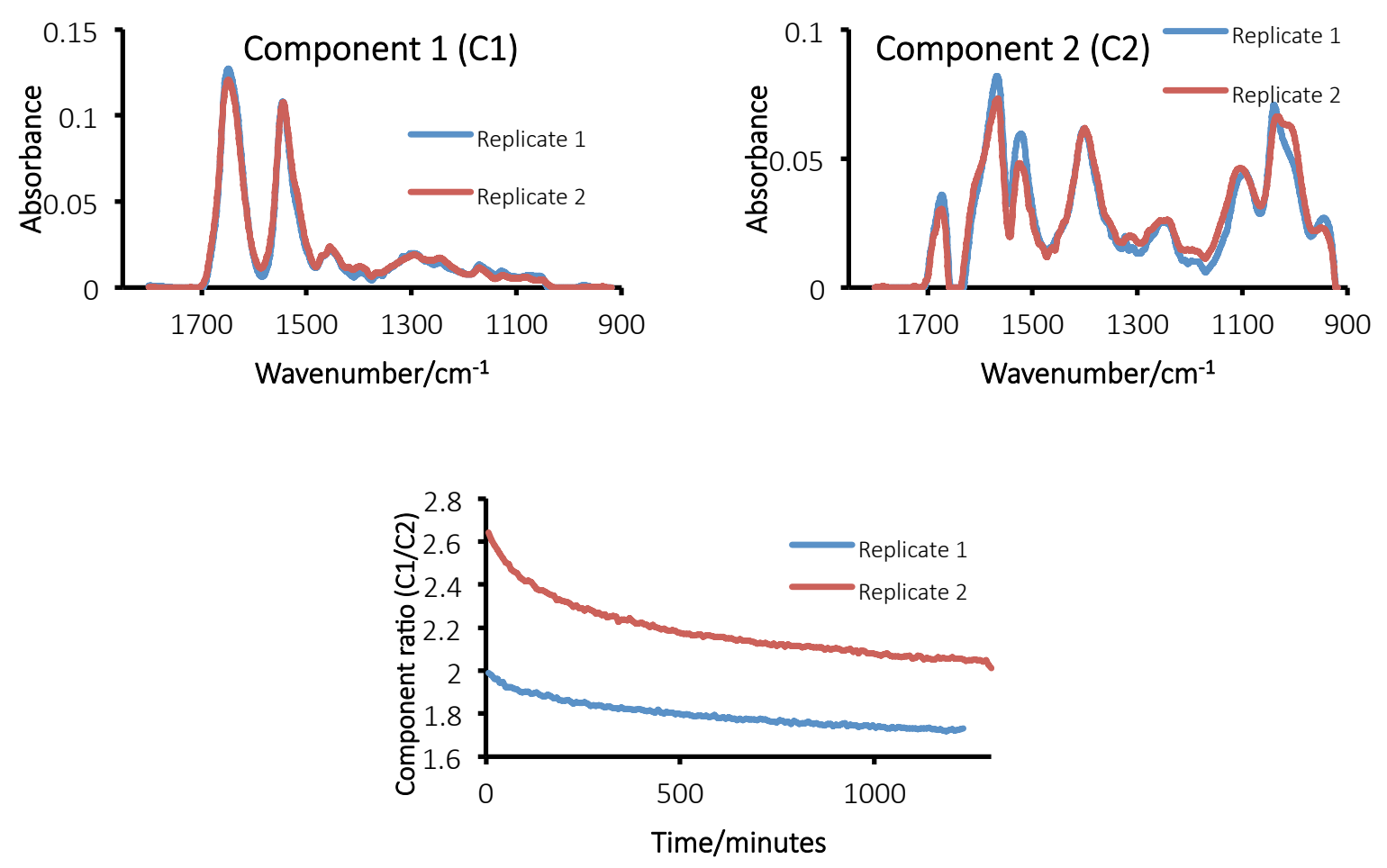

396 Figure S13. Multivariate curve resolution (MCR) analysis of replicate IR spectral data sets of

397 goethite-associated BSA during $20 \mathrm{~h}$ proteolysis reaction at $1.4 \mathrm{mg} \mathrm{BSA} \mathrm{m}{ }^{-2}$ collected in 
absence and presence of pre-adsorbed phosphate at $\mathrm{pH} 4.0$ in $0.01 \mathrm{M} \mathrm{NaCl}$. The mismatch in

399 the spectra of Component 2 in the top figure around $1630 \mathrm{~cm}^{-1}$ is most likely due to small 400 variations in interfacial water during one of the experiments. This shows that changes in the 401 region around this water bending mode should be interpreted with caution.

402

(A)

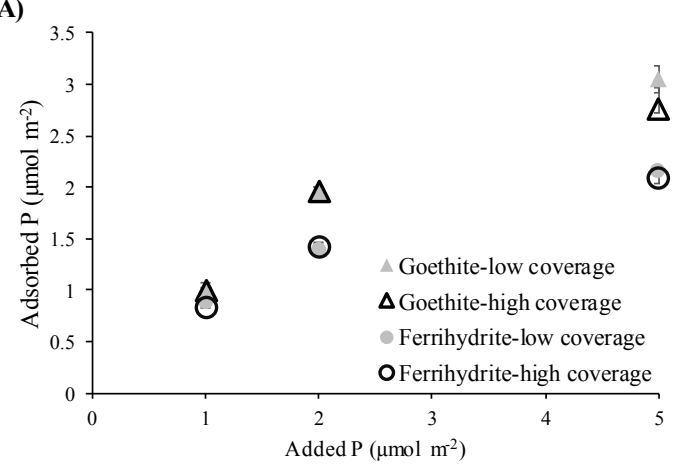

(B)

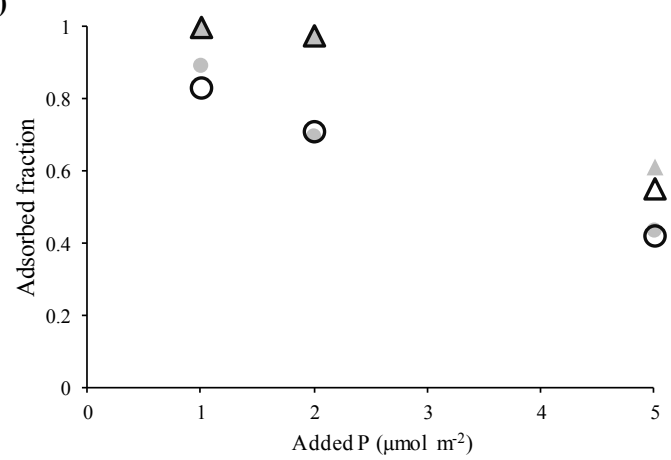

403

404 Figure S14. Phosphate adsorption on iron oxide-BSA associations at 0.7 (low coverage, solid 405

(A)

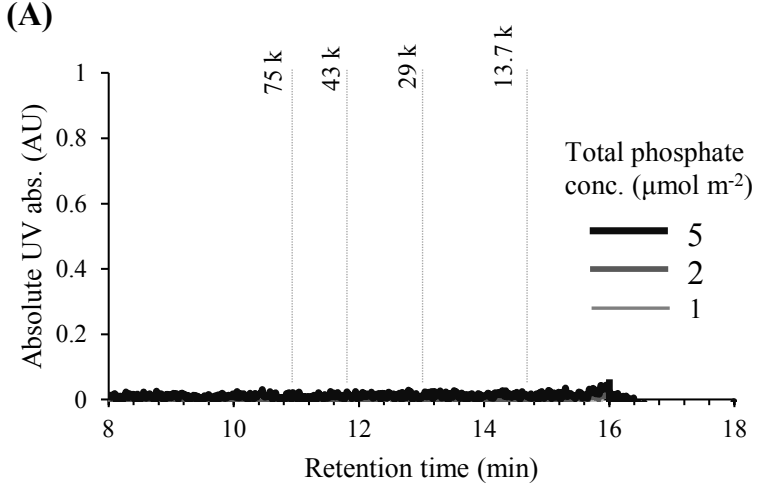

(B)

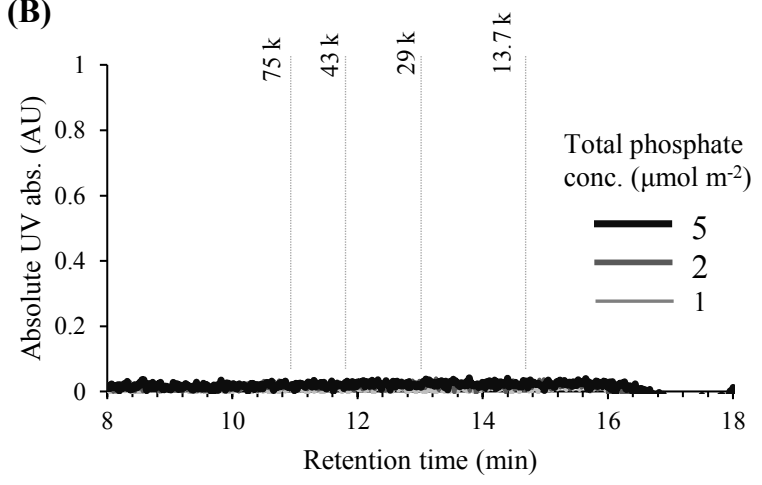

412 Figure S15. SEC chromatograms of ferrihydrite-associated BSA (A) and goethite-associated

413 BSA (B) after adsorption of phosphate. The experiments were performed at $0.7 \mathrm{mg} \mathrm{BSA} \mathrm{m}^{-2}$ 414 and $\mathrm{pH} 4.0$ in $0.01 \mathrm{M} \mathrm{NaCl}$ for $1.5 \mathrm{~h}$. The total phosphate concentrations were 1.0, 2.0 and 5.0 
$415 \mu \mathrm{mol} \mathrm{m} \mathrm{m}^{-2}$ and are given as numbers in the figure legends. The molecular masses (in Da) of 416 peptide standards are represented by the vertical dotted lines.
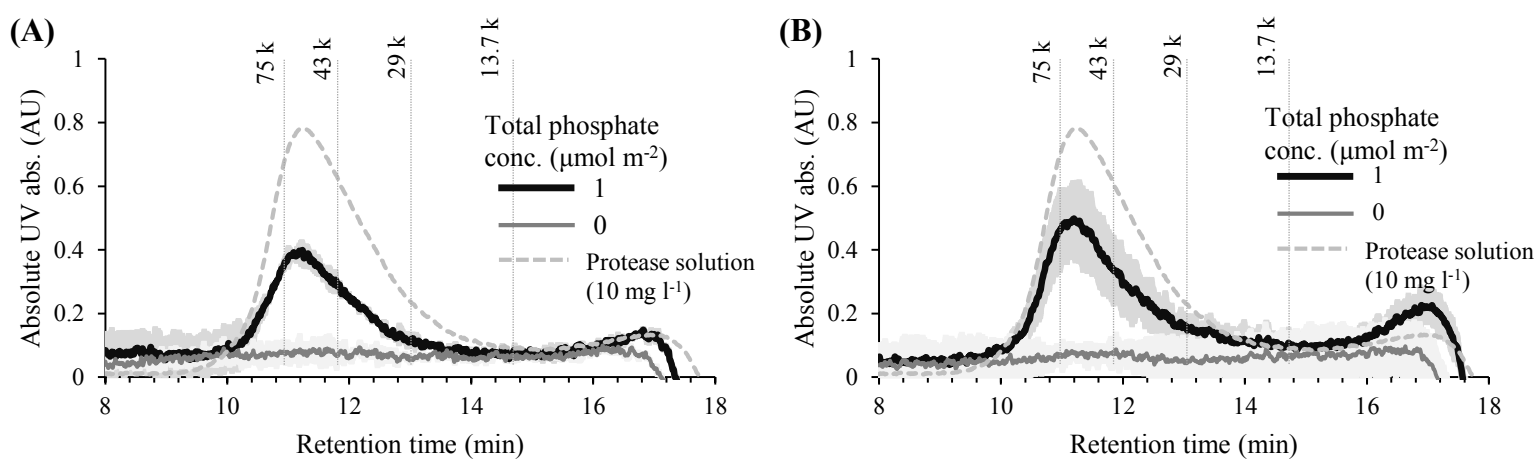

419 Figure S16. SEC chromatograms of the solution phases of ferrihydrite-associated BSA (A) 420 and goethite-associated BSA (B) in the presence of co-adsorbed phosphate after $3 \mathrm{~h}$ 421 proteolysis reaction. The experiments were performed at $0.7 \mathrm{mg} \mathrm{BSA} \mathrm{m}^{-2}$ and $\mathrm{pH} 4.0$ in 0.01 $422 \mathrm{M} \mathrm{NaCl}$, and the protease concentration was $10 \mathrm{mg} \mathrm{l}^{-1}$. The total phosphate concentrations 423 were 0 and $1.0 \mu \mathrm{mol} \mathrm{m}{ }^{-2}$ and are given as numbers in the figure legends. Dotted lines show 424 SEC chromatograms of a protease solution $\left(10 \mathrm{mg}^{-1}\right)$. Shaded bands represent standard 425 deviations $(\mathrm{n}=2)$. The molecular masses (in $\mathrm{Da})$ of peptide standards are represented by the vertical dotted lines.

(A)

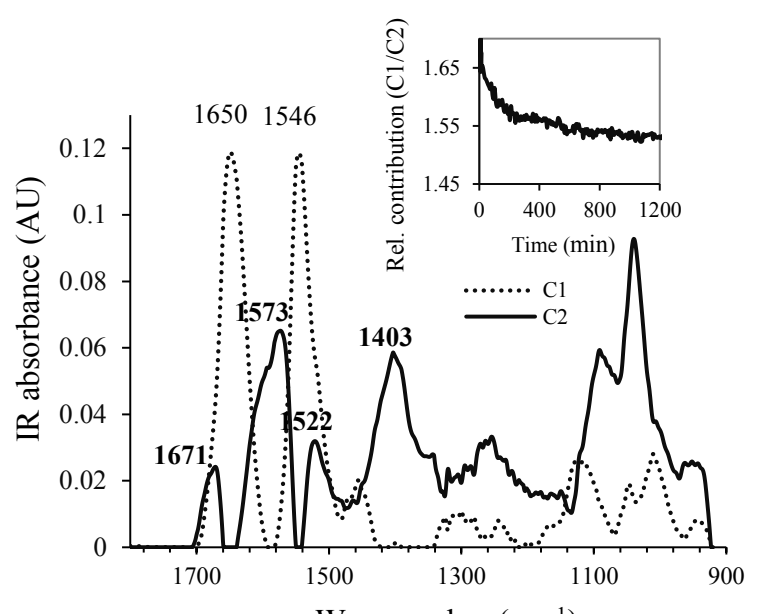

428
(B)

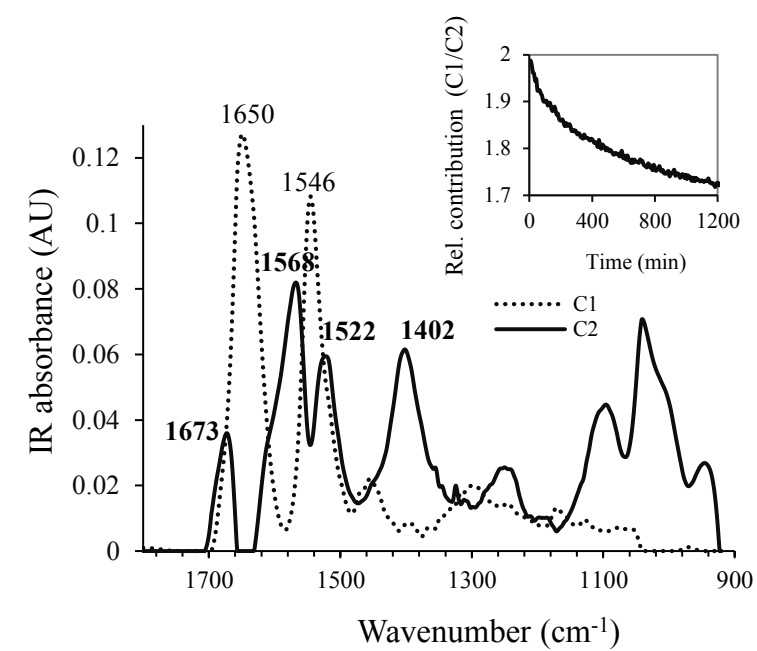

429 Figure S17. Multivariate curve resolution (MCR) analysis of IR spectral data sets of goethite430 associated BSA during $20 \mathrm{~h}$ proteolysis reaction at 0.7 (A, low coverage) and $1.4 \mathrm{mg} \mathrm{BSA} \mathrm{m}^{-2}$ 431 (B, high coverage). $1 \mu \mathrm{mol} \mathrm{m}{ }^{-2}$ of phosphate was adsorbed prior to enzyme addition $(+\mathrm{P} 1)$. 
432 The spectra of components 1 (C1) and 2 (C2) are presented as dotted and solid lines, 433 respectively, and the contribution from the $\mathrm{C} 1$ relative to $\mathrm{C} 2$ during the proteolysis are shown 434 in insets. The numbers in plain and bold text indicate the main peak positions of $\mathrm{C} 1$ and $\mathrm{C} 2$, 435 respectively.

436
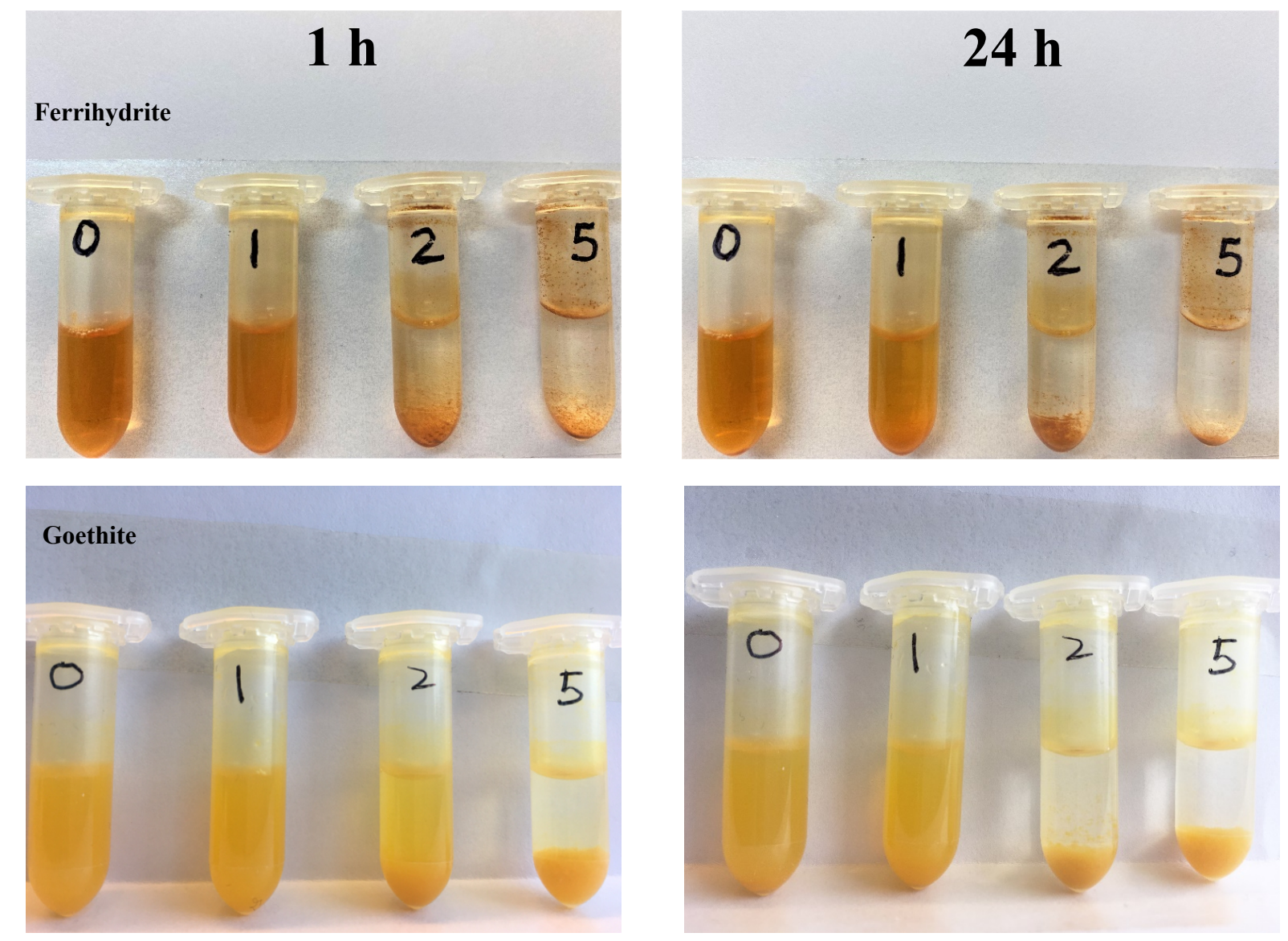

438 Figure S18. Time-dependent aggregation initiated by addition of phosphate to ferrihydrite439 associated BSA (upper panels) and goethite-associated BSA (lower panels). The experiments 440 were performed at a BSA surface coverage of $0.7 \mathrm{mg} \mathrm{m}^{-2}$ and $\mathrm{pH} 4.0$ in $0.01 \mathrm{M} \mathrm{NaCl}$. The 441 total phosphate concentrations were: $0,1,2,5 \mu \mathrm{mol} \mathrm{m}{ }^{-2}$ and are indicated by numbers on the 442 tubes. 
(A)

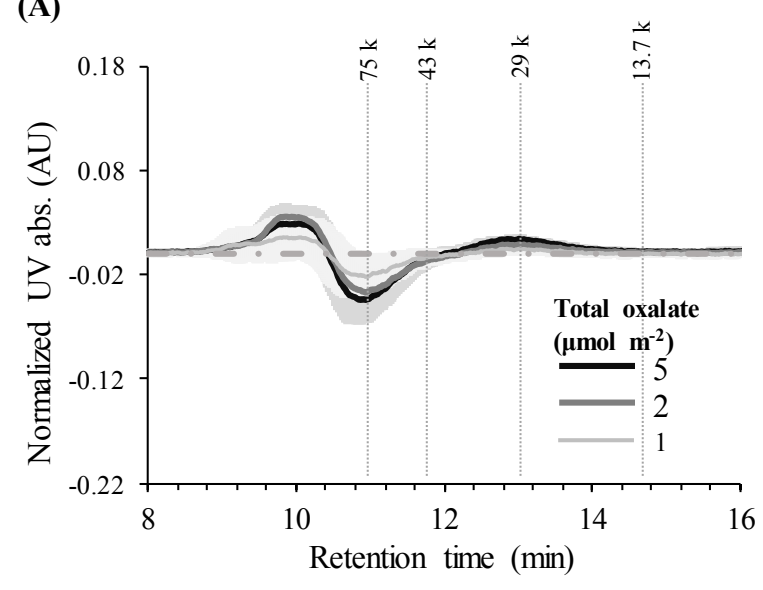

(B)

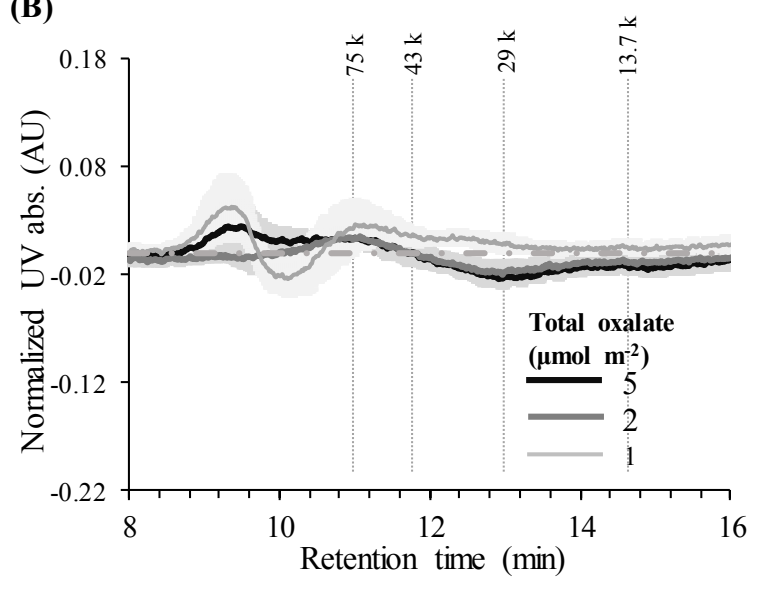

444

445 Figure S19. Difference SEC chromatograms of the phosphate-desorbed fraction of 446 ferrihydrite-associated BSA (A) and goethite-associated BSA (B) in the presence of pre447 adsorbed oxalate after $3 \mathrm{~h}$ proteolysis reaction. The experiments were performed at $0.7 \mathrm{mg}$ $448 \mathrm{BSA} \mathrm{m}{ }^{-2}$ and $\mathrm{pH} 4.0$ in $0.01 \mathrm{M} \mathrm{NaCl}$, and the protease concentration was $10 \mathrm{mg}^{-1}$. The total 449 oxalate concentrations were 1.0, 2.0 and $5.0 \mu \mathrm{mol} \mathrm{m} \mathrm{m}^{-2}$ and are indicated by numbers in the 450 figure legend. The chromatograms from samples prepared under identical conditions but in 451 absence of oxalate were subtracted from these chromatograms. The horizontal dotted lines 452 indicate the 0 -level. The shaded bands represent standard deviations $(n=2)$. The molecular 453 masses (in Da) of peptide standards are represented by the vertical dotted lines. Data were 454 analyzed only between 8-16 min in order to eliminate the interference from oxalate (which 455 has a retention time of $c a .17 \mathrm{~min}$ ) in the normalization procedure. 

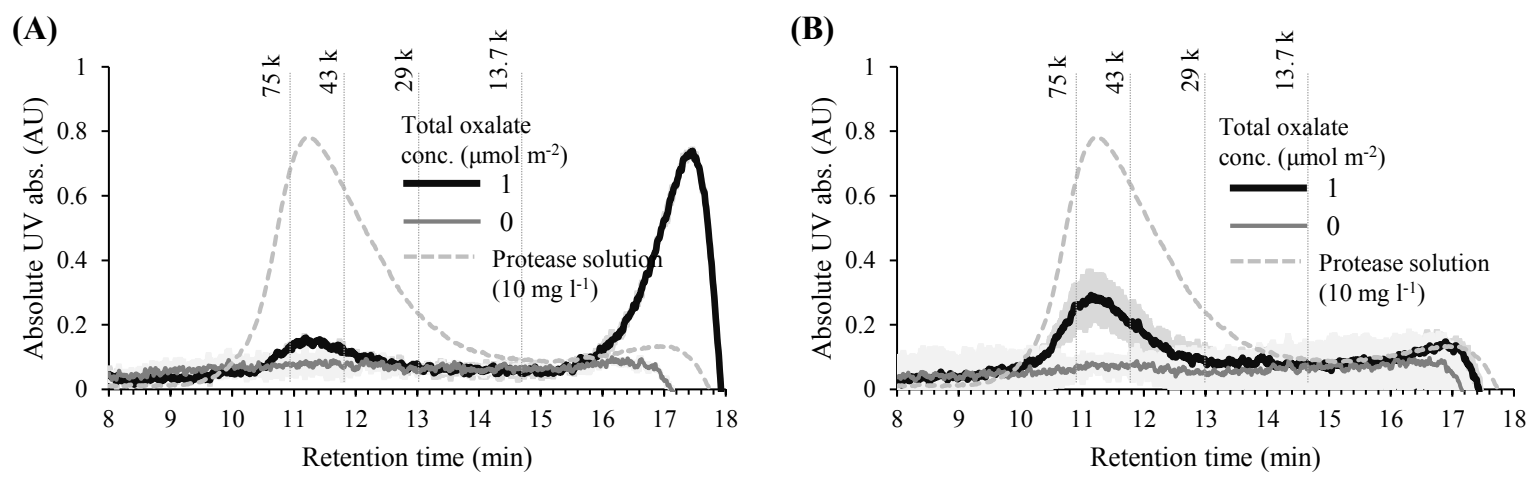

458 Figure S20. SEC chromatograms of ferrihydrite-associated BSA (A) and goethite-associated 459 BSA (B) in the presence of pre-adsorbed oxalate after $3 \mathrm{~h}$ proteolysis reaction. The 460 experiments were performed at $0.7 \mathrm{mg} \mathrm{BSA} \mathrm{m}^{-2}$ and $\mathrm{pH} 4$ in $0.01 \mathrm{M} \mathrm{NaCl}$, and the protease 461 concentration was $10 \mathrm{mg}^{-1}$. The total oxalate concentrations were 0 and $1.0 \mu \mathrm{mol} \mathrm{m}^{-2}$ and are 462 indicated by numbers in the figure legend. Dotted lines show SEC chromatograms of a 463 protease solution $\left(10 \mathrm{mg} \mathrm{l}^{-1}\right)$. Shaded bands represent standard deviations $(\mathrm{n}=2)$. The 464 molecular masses (in Da) of peptide standards represented by the vertical dotted lines. In (A) 465 the peak at ca. 17 min likely originates from oxalate in solution.
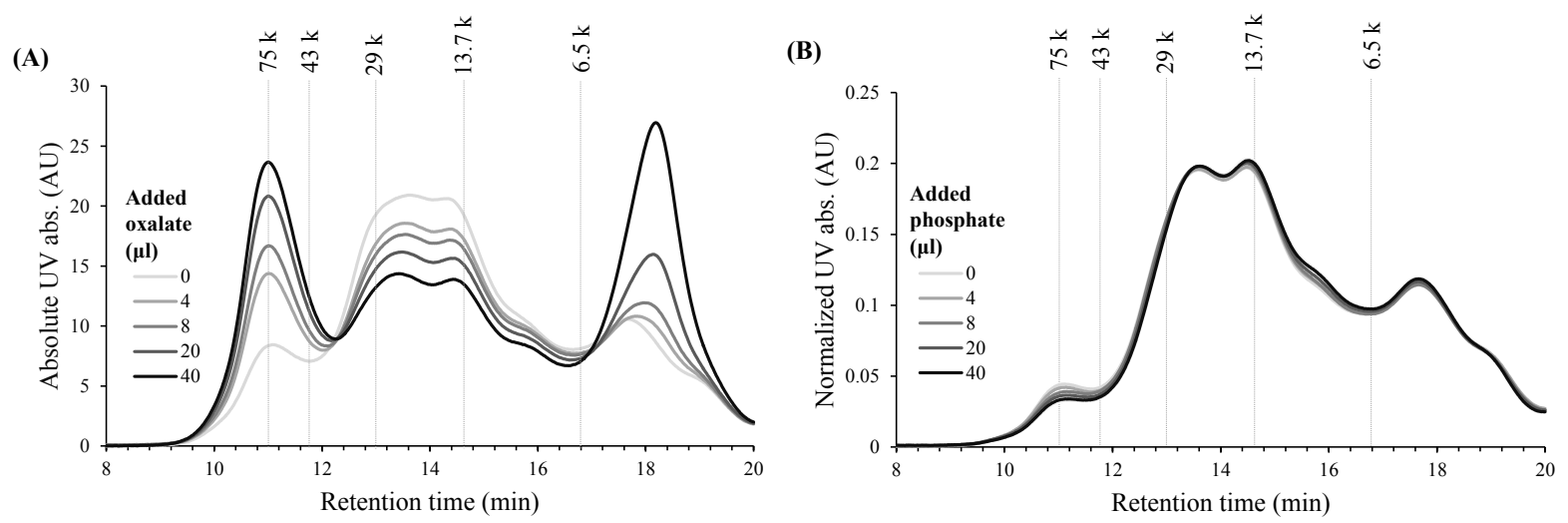

468 Figure S21. Effects of oxalate (A) and phosphate (B) on the proteolysis of aqueous BSA. The 469 experiments were performed in $1 \mathrm{ml}$ solution containing $100 \mathrm{mg} \mathrm{l}^{-1} \mathrm{BSA}$ and $10 \mathrm{mg} \mathrm{l}^{-1}$ 470 protease at $\mathrm{pH} 4.0$ in $0.01 \mathrm{M} \mathrm{NaCl}$ for $3 \mathrm{~h}$. The total amounts of phosphate or oxalate were 471 comparable to those of the co-adsorption experiments. The total volume of $15 \mathrm{mM}$ oxalate or 472 phosphate stock solutions are indicated in the figure legends and given in $\mu$. The molecular 
masses (in Da) of peptide standards are represented by the vertical dotted lines. The data presented are the average chromatograms of two replicates. In (B), the data were first areanormalized according to the total area below chromatograms ranging from 8 to $20 \mathrm{~min}$ and then averaged.

\section{References}

479 (1) Brunauer, S.; Emmett, P. H.; Teller, E. Adsorption of gases in multimolecular layers. J. Am. Chem. 480 Soc. 1938, 60, (2), 309-319.

481 (2) Krumina, L.; Lyngsie, G.; Tunlid, A.; Persson, P. Oxidation of a dimethoxyhydroquinone by 482 ferrihydrite and goethite nanoparticles: Iron reduction versus surface catalysis. Environ. Sci. Technol. 4832 2017, 51, (16), 9053-9061.

484 (3) Lyngsie, G.; Krumina, L.; Tunlid, A.; Persson, P. Generation of hydroxyl radicals from reactions 485 between a dimethoxyhydroquinone and iron oxide nanoparticles. Sci. Rep. 2018, 8, (1), 10834.

486 (4) Veneranda, M.; Aramendia, J.; Bellot-Gurlet, L.; Colomban, P.; Castro, K; Madariaga, J. M. FTIR spectroscopic semi-quantification of iron phases: A new method to evaluate the protection ability index (PAI) of archaeological artefacts corrosion systems. Corrosion Sci. 2018, 133, 68-77.

489 (5) Kuipers, B. J. H.; Gruppen, H. Prediction of molar extinction coefficients of proteins and peptides 490 using UV absorption of the constituent amino acids at $214 \mathrm{~nm}$ to enable quantitative reverse phase 491 high-performance liquid chromatography- mass spectrometry analysis. J. Agric. Food Chem. 2007, 55, 492 (14), 5445-5451.

493 (6) Chacon, S. S.; Reardon, P. N.; Burgess, C. J.; Purvine, S.; Chu, R. K.; Clauss, T. R.; Walter, E.; 494 Myrold, D. D.; Washton, N.; Kleber, M. Mineral surfaces as agents of environmental proteolysis: 495 Mechanisms and controls. Environ. Sci. Technol. 2019, 53, (6), 3018-3026.

496 (7) Murphy, J.; Riley, J. P. A modified single solution method for the determination of phosphate in 497 natural waters. Anal. Chim. Acta 1962, 27, 31-36.

498 (8) Holloway, W. D.; Argall, M. E.; Jealous, W. T.; Lee, J. A.; Bradbury, J. H. Organic acids and 499 calcium oxalate in tropical root crops. J. Agric. Food Chem. 1989, 37, (2), 337-341. 